ARTICLE

\title{
Ten-eleven translocation 1 mediated-DNA hydroxymethylation is required for myelination and remyelination in the mouse brain
}

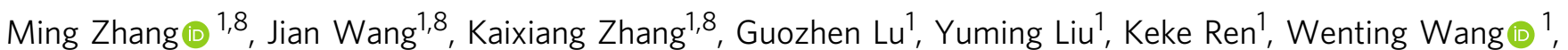
Dazhuan Xin ${ }^{2}$, Lingli Xu ${ }^{3}$, Honghui Mao ${ }^{1}$, Junlin Xing ${ }^{1}$, Xingchun Gao ${ }^{4}$, Weilin Jin $^{5}$, Kalen Berry (D) ${ }^{2}$,

Katsuhiko Mikoshiba (i) ${ }^{6,7}$, Shengxi Wu (i) ${ }^{1 凶}$, Q. Richard Lu (i) ${ }^{2 凶} \&$ Xianghui Zhao (iD ${ }^{1 凶}$

Ten-eleven translocation (TET) proteins, the dioxygenase for DNA hydroxymethylation, are important players in nervous system development and diseases. However, their role in myelination and remyelination after injury remains elusive. Here, we identify a genomewide and locus-specific DNA hydroxymethylation landscape shift during differentiation of oligodendrocyte-progenitor cells (OPC). Ablation of Tet1 results in stage-dependent defects in oligodendrocyte $(\mathrm{OL})$ development and myelination in the mouse brain. The mice lacking Tet1 in the oligodendrocyte lineage develop behavioral deficiency. We also show that TET1 is required for remyelination in adulthood. Transcriptomic, genomic occupancy, and 5-hydroxymethylcytosine $(5 \mathrm{hmC})$ profiling reveal a critical TET1-regulated epigenetic program for oligodendrocyte differentiation that includes genes associated with myelination, cell division, and calcium transport. Tet7-deficient OPCs exhibit reduced calcium activity, increasing calcium activity rescues the differentiation defects in vitro. Deletion of a TET1-5hmC target gene, Itpr2, impairs the onset of OPC differentiation. Together, our results suggest that stage-specific TET1-mediated epigenetic programming and intracellular signaling are important for proper myelination and remyelination in mice.

\footnotetext{
${ }^{1}$ Department of Neurobiology, School of Basic Medicine, Fourth Military Medical University, Xi'an, Shaanxi, China. ${ }^{2}$ Division of Experimental Hematology and Cancer Biology, Brain Tumor Center, Cincinnati Children's Hospital Medical Center, Cincinnati, OH, USA. ${ }^{3}$ Center for molecular medicine, Pediatric Research Institute, Children's Hospital of Fudan University, Shanghai, China. ${ }^{4}$ Shaanxi Key Laboratory of Brain Disorders, Xi'an Medical University, Xi'an, Shaanxi, China. ${ }^{5}$ Institute of Cancer Neuroscience, Medical Frontier Innovation Research Center, The First Hospital of Lanzhou University, Lanzhou, China. ${ }^{6}$ Faculty of Science, Toho University, Funabashi, Japan. ${ }^{7}$ Present address: Shanghai Institute for Advanced Immunochemical Studies, ShanghaiTech University, Shanghai, China. ${ }^{8}$ These authors contributed equally: Ming Zhang, Jian Wang, Kaixiang Zhang. ${ }^{{ }^{\circledR}}$ email: shengxi@fmmu.edu.cn; richard.lu@cchmc.org; xianghuizhao@fmmu.edu.cn
} 
$\mathrm{M}$ yelination by oligodendrocytes (OLs) enables saltatory conduction of action potentials and provides long-term trophic support for axons, maintaining integrity throughout the central nervous system $(\mathrm{CNS})^{1}$. The formation of mature myelinating OLs is a complex process that is tightly coordinated spatially and temporally by genetic and epigenetic events ${ }^{2,3}$. Epigenetic regulation by DNA methylation, histone modification, and chromatin remodeling is critical for multiple aspects of $\mathrm{OL}$ development, function, and regeneration ${ }^{4-6}$. For instance, proper maintenance of genomic 5-methylcytosine $(5 \mathrm{mC})$ is essential for normal development, homeostasis, and function of mammalian cells 7,8 . Genetic ablation of Dnmt1, which encodes the DNA methyltransferase that maintains DNA methylation after replication, results in impaired OL precursor cell (OPC) expansion and differentiation during early development ${ }^{9}$.

The modified nucleotide 5-hydroxymethylcytosine $(5 \mathrm{hmC})$ has been shown to be an intermediate product generated during cytosine demethylation ${ }^{10,11}$. DNA demethylation, like methylation, is a highly regulated process. DNA demethylation is mediated by the ten-eleven translocation (TET) family of dioxygenases. The TET enzymes oxidize $5 \mathrm{mC}$ into $5 \mathrm{hmC}$ to initiate the DNA demethylation process ${ }^{11,12}$. Dynamic regulation of cytosine methylation or demethylation has been established as a common epigenetic modification regulating various processes from development to diseases in a cell-type and context-dependent manner ${ }^{13-15}$. TET enzymes are present in OL lineage cells ${ }^{16}$, and here we interrogated how DNA demethylation contributes to OL lineage development, myelination, and remyelination after injury.

In this study, we demonstrate that there is a genome-wide shift in the $5 \mathrm{hmC}$ landscape during OL specification and identify an age-dependent function of TET1 in OL lineage specification and myelination. The mice with Tet1 deletion in OL lineage develop behavioral deficiency. In addition, we show that a TET1-regulated epigenetic program is required for efficient remyelination as depletion of Tet1 in OPCs impairs myelin recovery after demyelinating injury in adult animals. Moreover, Tet1 depletion resulted in genome-wide alterations in $5 \mathrm{hmC}$ and transcriptomic profiles that are associated with OPC differentiation and myelination, as well as calcium transport. Ablation of Itpr2, one of the TET1-5hmC targets that responsible for calcium release from endoplasmic reticulum (ER) in the OL lineage significantly impairs OL differentiation. These data suggest that TET1 and DNA hydroxymethylation mediated transcriptional and epigenetic programming regulate OL intracellular signaling and are required for proper myelination and animal behaviors.

\section{Results}

Dynamic DNA hydroxymethylation landscape during OL lineage specification. To investigate the $5 \mathrm{hmC}$ landscape during OL lineage specification, we carried out antibody-based $5 \mathrm{hmC}$ immunoprecipitation (IP) combined with Illumina sequencing $(\mathrm{hMeDIP} \text {-seq) })^{17,18}$ and analyzed $5 \mathrm{hmC}$ distribution across the genome. We compared the $5 \mathrm{hmC}$ distribution within OPCs isolated via immunopanning from the cortices at postnatal day 6 (P6) to that in neural progenitor cells (NPCs) $)^{19}$ and identified 1237 genes that were specifically hydroxymethylated in the promoter or transcription start site (TSS) regions of OPCs but not NPCs (Fig. 1a). Gene ontology (GO) analysis revealed that these genes involved in OPC differentiation are highly associated with terms such as cell projection organization, fatty acid transport, and regulation of cytosolic calcium ion concentration, and with signaling pathways that are essential for OL development such as the G-protein coupled receptor pathway ${ }^{20,21}$ (Fig. 1b). Similarly, gene set enrichment analysis (GSEA) for $5 \mathrm{hmC}$ peaks in the gene body regions indicated that genes associated with the bipotent progenitor, OL progenitor, and postmitotic OL were enriched in OPCs (Fig. 1c), while pluripotent stem cell-associated genes were enriched in NPCs (Fig. 1c). Comparison with a neural cell-type transcriptome dataset ${ }^{2}$ (Supplementary Fig. 1a-c) showed that the $5 \mathrm{hmC}$ signals were higher in OPCs than NPCs, in gene loci of OPC-associated genes, e.g., Cspg4 (chondroitin sulfate proteoglycan 4) (Fig. 1d), immature OL-associated genes, e.g., Kndcl (kinase non-catalytic C-lobe domain containing 1) (Fig. 1e), and mature OL-associated genes, e.g., Mag (myelin-associated glycoprotein) (Fig. 1f). In contrast, the genes with $5 \mathrm{hmC}$ peaks enriched in NPCs were associated with negative regulation of OPC differentiation, such as $N g f$ and $Z f p 28$ (Fig. $1 \mathrm{~g}$ ). We further verified the presence of loci-specific hydroxylmethylation in representative genes with a qPCR assay based on a combination of bisulfite and subsequent cytosine deaminase (APOBEC) treatment (Supplementary Fig. 1d and Supplementary Table 1). These data suggested a unique distribution pattern of genomic $5 \mathrm{hmCs}$ in the gene loci associated with OL lineage specification during the transition from NPCs to OPCs.

Deletion of Tet1 in OL lineage causes myelination deficits at early postnatal stages. TET1-3 enzymes are present in OL lineage cells $^{16}$. As TET2 had no detectable effects in OL lineage development ${ }^{23}$, we assessed the functions of TET1 and TET3 in OL development. We crossed Tet $1^{\text {flox/flox }}$ mice ${ }^{24}$ and Tet $3^{\text {flox/flox }}$ mice $^{18}$ with the Olig1-Cre line ${ }^{25}$ to knockout the catalytic domains of these TET enzymes early in OL lineage development (Fig. 2a and Supplementary Fig. 2a). The resulting Tet $1^{\text {flox/flox}} ;$ Olig1Cre ${ }^{+/-}\left(\right.$Tet1 cKO) and Tet $3^{\text {flox/flox }} ;$ Olig1Cre ${ }^{+/-}$ (Tet3 cKO) mice were born at Mendelian ratios and appeared normal at birth. We did not detect significant differences in either the number of $\mathrm{CCl}^{+}$mature OLs or myelin protein expression between heterozygous Tet1-floxed mice (Tet $1^{\text {flox/+}}$;Olig1Cre $\left.{ }^{+/-}\right)$, Cre control ( Tet $1^{+/+} ;$Olig1Cre $\left.{ }^{+/-}\right)$, or wild-type mice (Supplementary Fig. 3a, b). Also, we did not detect any OLIG2 expression changes within the Olig1-Cre $(+/-)$ heterozygous line (Supplementary Fig. 3c, d). Therefore, heterozygous littermates were used as controls. To assess Cre-mediated Tet1 depletion in OL lineage, we quantified TET1 expression in OPCs from Tet $1 \mathrm{cKO}$ and control mice at $\mathrm{P} 4$. Immunostaining revealed that expression of TET1 in SOX $10^{+}$OLs was significantly reduced in Tet $1 \mathrm{cKO}$ than in control mice (Fig. 2b, c). TET1 levels were also decreased in purified OPCs from Tet 1 mutant than from control mice assayed by quantitative real-time PCR (Supplementary Fig. 3e). To examine the cell-type or lineage-specificity of Olig1-Cre in the postnatal brain, we have generated Olig1-Cre; R26-tdTomato mice by crossing the Olig1-Cre mice with R26-tdTomato reporter line (Ai14). We found that most Olig1-Cre-TdTomato cells were OLIG2-positive OL lineage cells (Supplementary Fig. 3f, g), while TdTomato $^{+}$cells rarely co-label with the markers for astrocytes $\left(\mathrm{ALDH}_{1 \mathrm{~L}}{ }^{+}\right)$, neurons $\left(\mathrm{NeuN}^{+}\right)$, or interneurons $\left(\mathrm{PV}^{+}, \mathrm{SST}^{+}\right.$, and $\mathrm{VIP}^{+}$) (Supplementary Fig. 3f, h, i), indicating that the Olig1Cre line is predominantly restricted to the OL lineage.

To investigate the effects of TET1 on OL development in the brain, we examined the expression of OL lineage marker SOX10 and mature OL markers CC1 and MBP. The number of $\mathrm{CC}^{+}$ mature OLs was significantly reduced in juvenile Tet 1 cKO mice compared to controls (Fig. 2d, e), but this difference was not observed in adult mice from P52 (Fig. 2e and Supplementary Fig. 4a). Expression of MBP was also substantially decreased in both cortex (gray matter) and corpus callosum (white matter) in Tet1 cKO mice compared to controls at P16 (Fig. 2f), but the levels were similar in P60 adult animals (Supplementary Fig. 4b). 

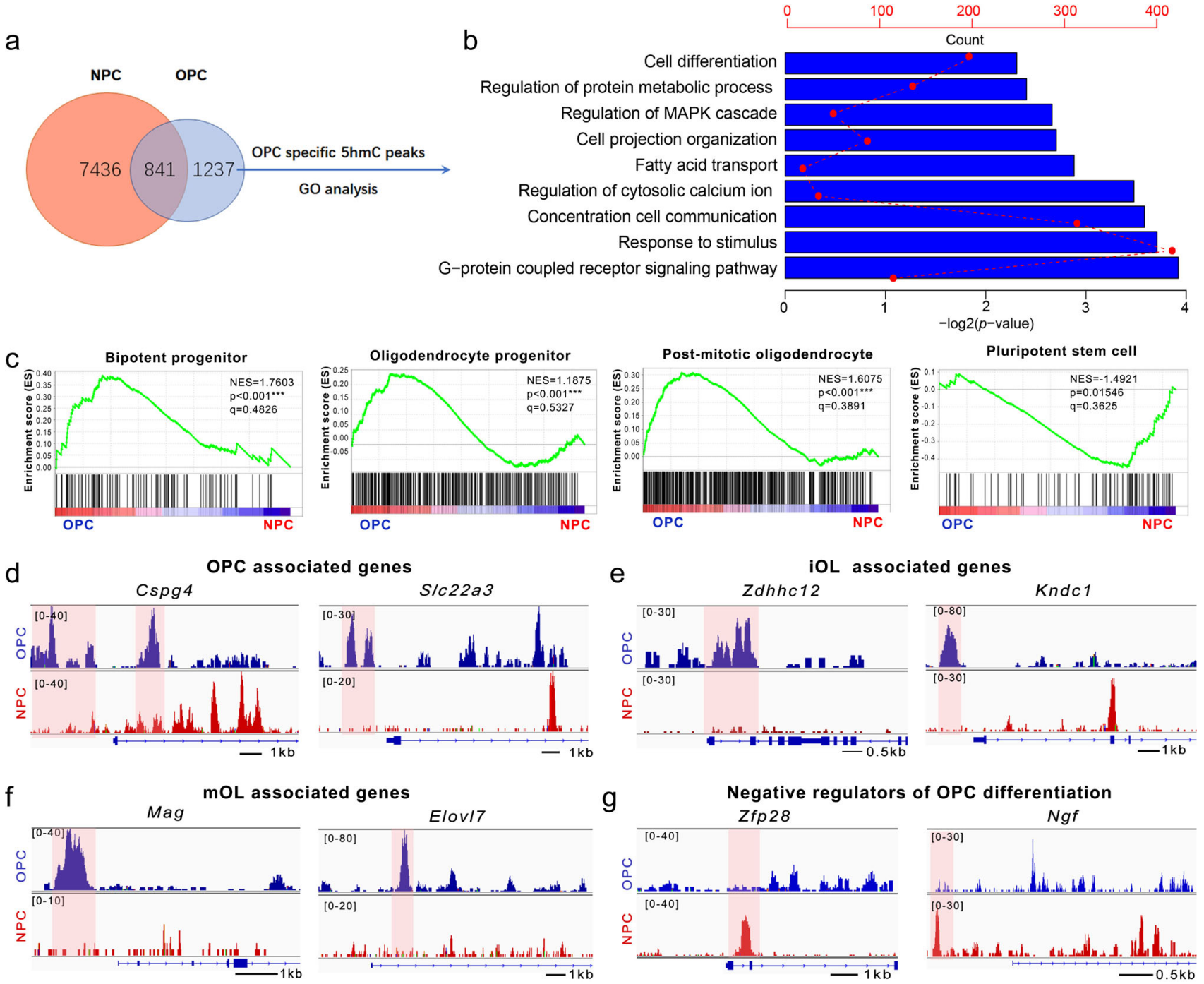

Fig. 1 Dynamic 5hmC expression pattern during OPC specification. a Venn diagram of hydroxymethylated genes in NPCs (neural progenitor cells) and OPCs (oligodendrocyte progenitor cells). b Gene ontology (GO) analysis of genes with OPC-specific $5 \mathrm{hmC}$ peaks in promoter or TSS regions. c GSEA plots of gene terms involved in "bipotent progenitor", "oligodendrocyte progenitor", "postmitotic oligodendrocyte", and "pluripotent stem cell" for genes with $5 \mathrm{hmC}$ peaks in gene body region from NPCs and OPCs. d Snapshots of $5 \mathrm{hmC}$ profiles of representative OPC-associated genes, Cspg4 and S/c22a3, in NPCs and OPCs. Tracks were shown in IGV 2.4.8. e Snapshots of $5 \mathrm{hmC}$ profiles of representative immature oligodendrocyte (iOL)-associated genes, Zdhhc12 and Kndc1, in NPCs and OPCs. f Snapshots of 5hmC profiles of representative mature oligodendrocyte (mOL)-associated genes, Mag and Elovl7, in NPCs and OPCs. $\mathbf{g}$ Snapshots of $5 \mathrm{hmC}$ profiles of representative negative regulators of oligodendrocyte differentiation, Ngf and Zfp28 in NPCs and OPCs.

These data are consistent with previous observations with a siRNA-mediated knockdown in rat OPC culture ${ }^{16}$ and indicate that Tet1 loss causes a delay in OL maturation. Similar experiments in the Tet 3 cKO animals did not show any significant differences between mutants and controls (Supplementary Fig. 2), which is different from previous in vitro data using siRNA-mediated knockdown ${ }^{16}$. We speculate that this might be due to the possible off-target effects of TET3 siRNA on other TET members or other unidentified factors crucial for OPC differentiation. Therefore, we focused on examining the processes underlying the observed myelination defects in Tet $1 \mathrm{cKO}$ mice.

In addition, electron microscopy (EM) revealed that the number of myelinated axons was significantly reduced in Tet 1 mutants compared to controls at both P14 optic nerves and P27 corpus callosum (Fig. 2g, h, j). Moreover, those myelinated axons in Tet1 cKO mice were characterized by higher $\mathrm{G}$ ratios and thinner myelin sheaths than those of control mice (Fig. 2i, k). However, the myelin ultrastructure defects were not observed in P60 adult Tet 1 cKO animals (Supplementary Fig. 4c-e). Together, these results suggest a stage-dependent function of TET1 in CNS myelination.

Consistent with the observation, we confirmed here that TET1 expression significantly decreased in control adult OLs (Supplementary Fig. 4f, g). However, in Tet1 cKO mice at P60, the number of TET $1+$ OLs increased to $29 \%$ (Supplementary Fig. 4f, g), which is higher than $\sim 12 \%$ in Tet $1 \mathrm{cKO}$ animals at P4 (Fig. $2 \mathrm{~b}$, c). This result indicates that OPCs failed to disrupt TET1 expression may contribute to the recovery of myelin formation in older mutant animals.

To evaluate the neurological significance of hypomyelination in Tet 1 cKO mice, we analyzed stimulus-evoked compound action potential (CAP) in P14 optic nerves as previously described ${ }^{26,27}$. Suction electrodes backfilled with artificial cerebrospinal fluid (aCSF) were used for stimulation and recording. In Tet1 mutants, both the peak amplitudes and the CAP areas, which are indexes of excited myelinated axon numbers and nerve function ${ }^{26,27}$, were significantly lower than controls under all stimulating currents tested (Fig. 2l-n). This observation indicates that 
a

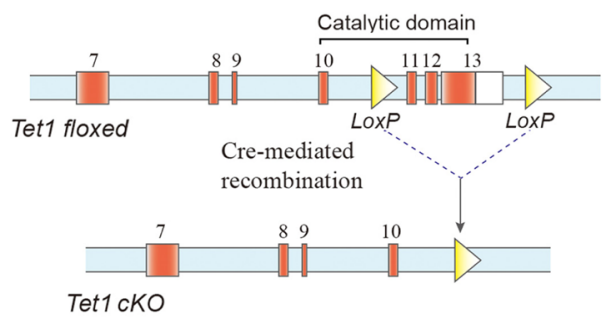

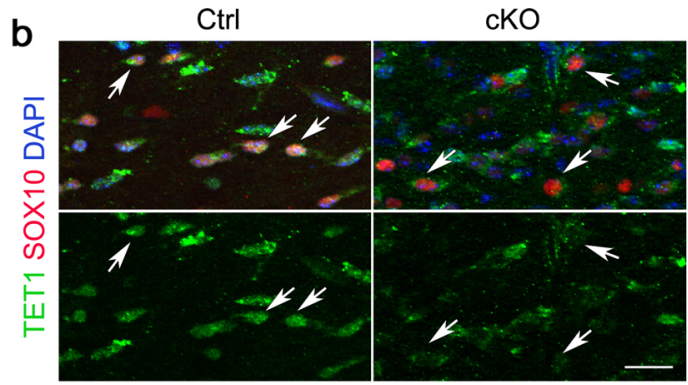

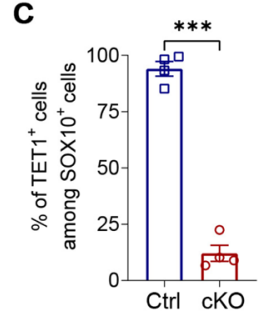



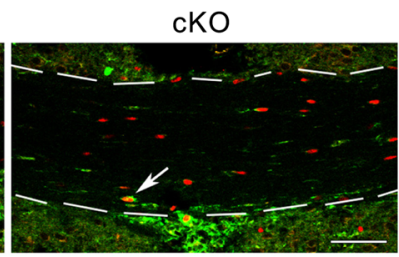

e

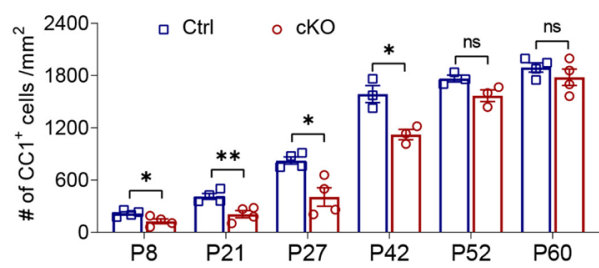

g

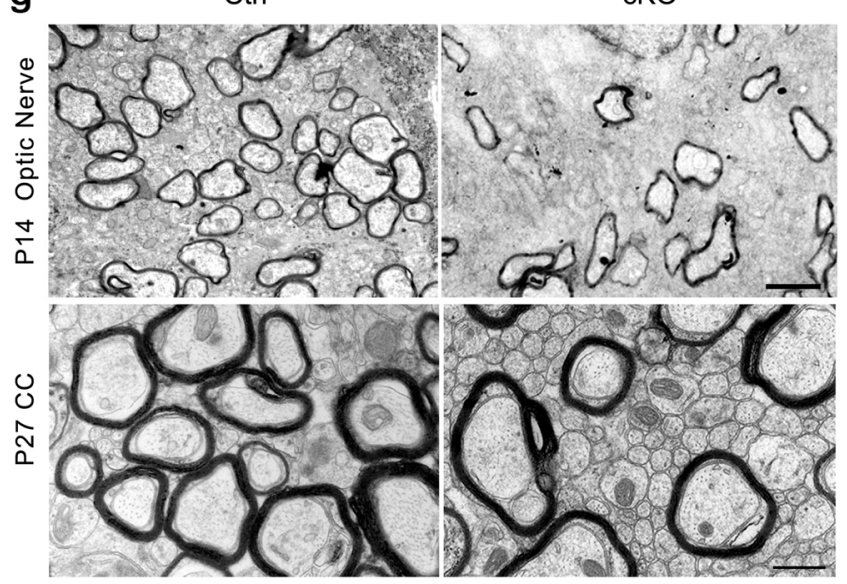

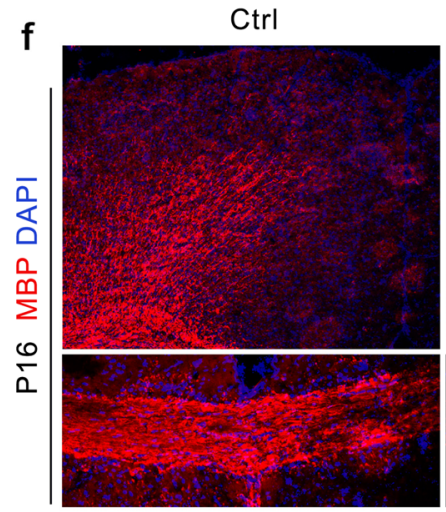

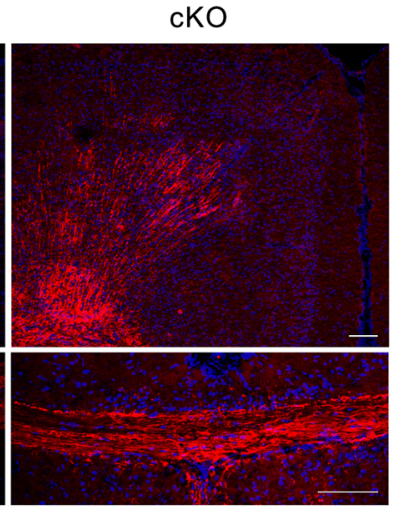

h
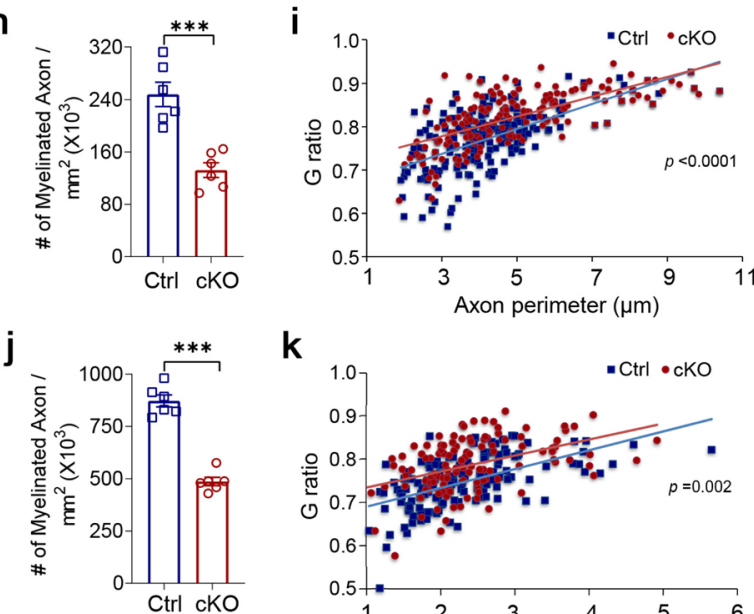

k
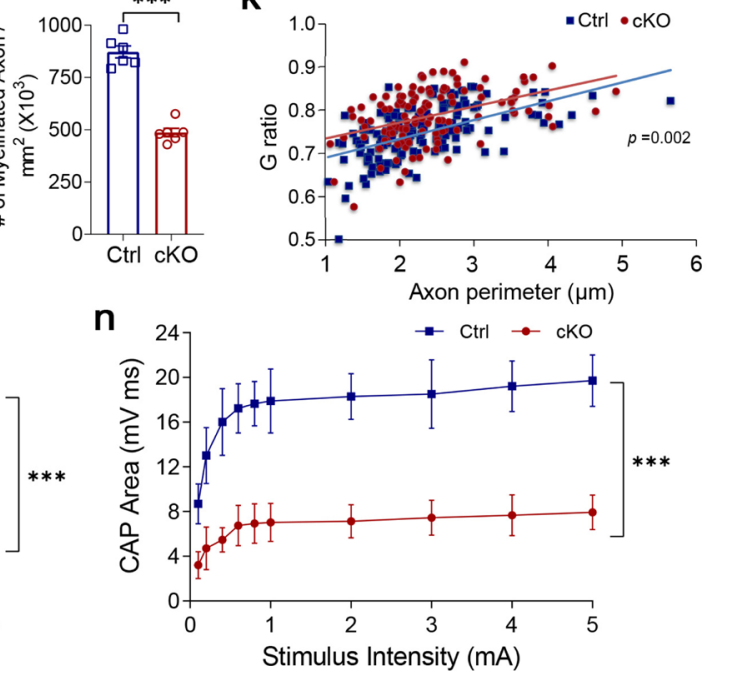
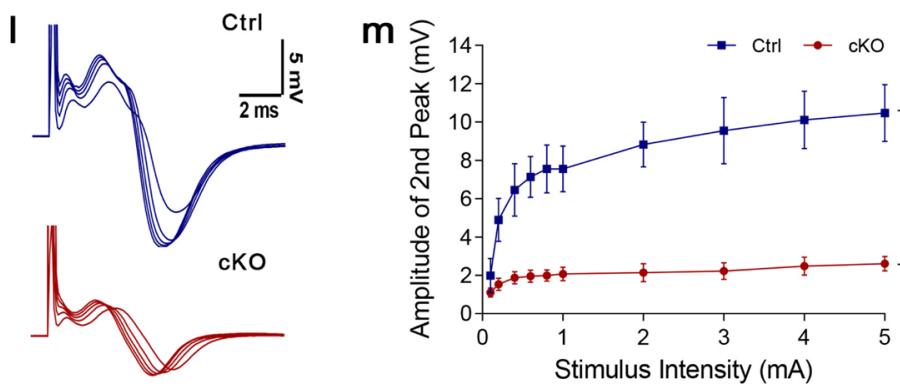

hypomyelination impairs action potential transduction in Tet1 cKO mice.

Loss of TET1 function in OL lineage cells induces behavioral deficiency in the mice. Multiple studies have associate TET$5 \mathrm{hmC}$ with psychiatric and cognitive disorders ${ }^{28-30}$, and multivariable logistic regression showed that ERBB4, BDNF, and TET1 were independent predictors for schizophrenia ${ }^{31}$. To gain insight into the physiological function of TET1 in animal behaviors, Tet 1
cKO mice were subjected to behavior tests relevant to schizophrenia. Tet 1 cKO mice did not exhibit differences in weight and whisker number in comparison with control littermates.

First, we investigated the performance of juvenile Tet 1 mutant in prepulse inhibition (PPI) of the startle test at P42 with myelin deficiency (Supplementary Fig. 5a), which is a common test of sensorimotor gating ability for schizophrenia ${ }^{32}$. Reduced PPI ability due to an exaggerated acoustic startle reflex (ASR) is thought to contribute to schizophrenic conditions. We found that the 
Fig. 2 TET1 is required for OL differentiation and myelination. a Schematic diagram of Cre-mediated excision of floxed Tet1 exons encoding the critical catalytic domain for dioxygenase activity. b Representative immunostaining for TET1 expression in postnatal day 4 (P4) corpus callosum from control (Ctrl) and Tet1 cKO (cKO) mice. Upper images show TET1 (green), SOX10 (red), and DAPI (blue) staining. Lower images show only TET1. Arrows indicate SOX10+ cells. Scale bar, $20 \mu \mathrm{m}$. c Percentage of TET1+ cells among SOX10+ oligodendrocytes in P4 corpus callosum of control and Tet1 cKO mice. Data were Means \pm SEM ( $n=4$ animals in each group). ${ }^{\star \star \star}$, Two-tailed unpaired $t$-test, $t=17.091, d f=6, p=0.000003$. $\mathbf{d}$ Representative images of CC1 and SOX10 immunostaining in the corpus callosum of control and Tet1 cKO mice at P8. Scale bar, $50 \mu \mathrm{m}$. e Quantification of CC1+ cells in P8, P21, P27, P42, P52, and P60 control and Tet1 cKO corpus callosum. Data were Means \pm SEM ( $n=3$ animals in P42 and P52 for each group, $n=4$ animals in P8, P21, P27, and P60 for each group). Two-tailed unpaired $t$-test, ${ }^{*}, \mathrm{P} 8: t=2.724, d f=6, p=0.034 ;{ }^{*}, \mathrm{P} 21: t=3.794, d f=6, p=0.009 ;{ }^{*}, \mathrm{P} 27: t=3.702, d f=6, p=0.010 ;{ }^{*}, \mathrm{P} 42: t=4.071, d f=4, p=0.015 ;$ P52: $t=2.529, d f=4, p=0.065 ; \mathrm{P} 60: t=1.036, d f=6, p=0.340$ compared to control. $\mathbf{f}$ Representative images of MBP immunostaining in Tet1 cKO and control mice cortex (upper images) and corpus callosum (lower images) at P16. Scale bar, $100 \mu \mathrm{m}$. $\mathbf{g}$ Representative electron micrographs of P14 optic nerve and P27 corpus callosum (cc) from control and Tet1 cKO mice. Scale bar, $0.5 \mu \mathrm{m}$ in P14 and $2 \mu \mathrm{m}$ in P27, respectively. $\mathbf{h}$ Quantification of the number of myelinated axons in defined areas from the optic nerve of P14 control and Tet1 cKO mice. Data were Means \pm SEM ( $n=6$ slides from three animals per group). $\star \star \star$, Two-tailed unpaired $t$-test, $t=5.308, d f=10, p=0.000344$ compared to control. $\mathbf{i} \mathrm{G}$ ratios vs. axonal perimeters for P14 optic nerve in control and Tet 1 cKO mice. Friedman $M$ test, $\chi^{2}=43.251, d f=1, p_{\text {between group }}<0.0001$ ( $>150$ myelinating axon counts/animal from three animals/genotype). $\mathbf{j}$ Quantification of the number of myelinated axons in defined areas from corpus callosum of P27 control and Tet 1 cKO mice. Data were Means \pm SEM ( $n=6$ slides from three animals per group). ${ }^{\star \star \star}$, Two-tailed unpaired $t$-test, $t=11.050, d f=10, p<0.0001$ compared to control. $\mathbf{k} \mathrm{G}$ ratios vs. axonal perimeters for $\mathrm{P} 27$ corpus callosum in control and Tet1 cKO mice. Two-way ANOVA, $F_{\text {between group }(1,58.597)}=10.806, F_{\text {within group }(3,3)}=71.262, p_{\text {between group }}=0.002(>120$ myelinating axon counts/animal from three animals/genotype). I Representative compound action potential (CAP) series from optic nerves of P14 control and Tet1 cKO mice elicited by square voltage pulses of varied amplitudes. $\mathbf{m}$ Evoked CAP amplitudes of the second peak (maximal) from control and Tet1 cKO mice plotted vs.

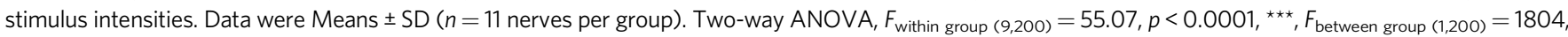
$p<0.0001$. $\mathbf{n}$ Total CAP area vs. stimulus intensities in controls and Tet $1 \mathrm{cKO}$ mice at all stimulus intensities compared. Data were Means \pm SD $(n=11$ nerves

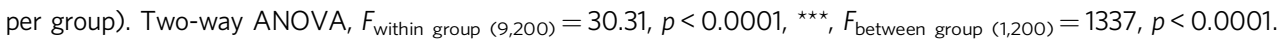

input/output function and the startle response were comparable between control and Tet1-mutant mice (Supplementary Fig. 5b), indicating the normal hearing and motor abilities (i/o function) in Tet 1 cKO mice. However, when using a combination of auditoryevoked startle $(120 \mathrm{~dB})$ and three levels of prepulse $(70,76$, and $82 \mathrm{~dB}$ ) to compare ARS, we observed that PPI was significantly attenuated in Tet $1 \mathrm{cKO}$ mice in comparison with control animals (Supplementary Fig. 5c), suggesting the impaired sensorimotor gating ability in Tet1 mutant.

Since working memory deficits are characteristic features in schizophrenia, adult Tet1 cKO mice and control littermates at P90 were evaluated for their performance in the Morris water maze (MWM) to assess their working memory. Consistently, the myelin deficiency in Tet1 cKO mice was recovered after P60 (Supplementary Fig. 4), including the hippocampus that is associated with spatial reference memory ${ }^{33}$ (Supplementary Fig. 5d). Five-day acquisition trials exhibited similar swim paths, swim velocity, and escape latency to the platform between control and Tet $1 \mathrm{cKO}$ groups (Supplementary Fig. $5 \mathrm{e}-\mathrm{g}$ ), which indicates that adult Tet 1 mutants had normal swimming and learning abilities. However, in the sixth-day probe trial, the escape latency was significantly higher in Tet1 cKO mice than in control mice (Supplementary Fig. 5h), and the number of crossing the position was greatly reduced in mutant mice (Supplementary Fig. 5i). Additionally, in contrast to controls, Tet1 cKO mice showed no preference for the target quadrant over other three quadrants (Supplementary Fig. 5j, k). These observations indicate that developmental myelinogenesis may contribute to working memory deficits in Tet1-mutant animals. Together, our results suggest that the abnormal myelination in Tet1 cKO mice may cause behavioral deficiency with impaired sensorimotor gating ability and working memory.

\footnotetext{
Ablation of Tet1 results in defects in OPC cell-cycle progression. Concomitant with the myelin deficiency, we observed a marked reduction of OLIG2 ${ }^{+}$cells from embryonic stage E15.5 and at P1 in Tet1 cKO cortex relative to controls (Fig. 3a, b). Moreover, the number of PDGFRa ${ }^{+}$OPCs in the mutant cortex was significantly reduced at E15.5 and P1 (Fig. 3a, c), suggesting a downsized OPC pool in Tet1 cKO brain. Interestingly, the difference of OPC number between Tet 1 mutant and control brains was not obvious after P6 (Fig. 3c). We speculate that this may in
}

part be due to the substantial decline in TET1 expression with age particularly after $\mathrm{P} 4{ }^{16}$, suggesting a less critical role for TET1 in later stages of OPC development. In addition, it is possible that compensation from other TETs (e.g., TET2 and TET3) might also contribute to OPC development in the Tet1 cKO mice.

To determine the underlying defects that led to the observed reduction in the OPC and OL population in juvenile Tet 1 mutants, we first tested the possibility that OPCs are more likely to undergo apoptosis in the mutant with the TUNEL assay. Brain sections from E14.5, E17.5, and P1 mice revealed no distinguishable changes in the number of apoptotic cells among OLIG2+ OL lineage cells between Tet $1 \mathrm{cKO}$ animals and control littermates (Supplementary Fig. 6a, b).

Next, we performed a BrdU incorporation assay to examine the proliferation of OPCs. At P1, mice were dosed with BrdU and sacrificed $2 \mathrm{~h}$ later. Compared to controls, intriguingly, the percentage of $\mathrm{BrdU}^{+}$cells in OLIG2 ${ }^{+} \mathrm{OL}$ lineage cells showed a significant increase in Tet1 cKO cortex (Fig. 3d, e). However, BrdU incorporation in older mice, e.g., P20 and P60, did not reveal the difference in OPCs between groups (Supplementary Fig. 6c-f). In addition, we examined the proliferation changes in purified OPC cultures. Both BrdU incorporation and Ki67 staining showed increased proliferating OPCs from Tet1 mutants (Supplementary Fig. $6 \mathrm{~g}-\mathrm{i})$.

The reduction of OPC numbers in Tet1 cKO mice thus promote us to investigate if there is a cell-cycle defect in Tet1-deficient OPCs. Then we performed flow cytometry for purified OPCs in which DNA was stained with propidium iodide. Significant increases in the percentages of cells in the $\mathrm{S}$ phase $(23.49 \pm 0.85 \%)$ and $\mathrm{G} 2 / \mathrm{M}$ phase $(13.39 \pm 1.01 \%)$ were observed in OPCs from Tet 1 mutants compared to the controls $(9.02 \pm 0.99 \%$ for $S$ phase and $8.29 \pm 0.62 \%$ for G2/M phase) (Fig. 3f, g and Supplementary Fig. 7a, b). Moreover, there was a concomitant reduction in the number of cells in the G1 phase in Tet1 mutants compared to the controls (Fig. 3f, g).

A recent report has suggested the critical role of TETs in regulating the $\mathrm{G} 2$ to $\mathrm{M}$ phase progression of trophoblast stem cells $^{34}$, we then tested G2-M progression of Tet1 cKO OPCs in a cell cycle synchronization assay. We arrested cell cycle at G2/M with the CDK1 inhibitor RO3306 for $12 \mathrm{~h}$, followed by a release at specific time points (Fig. 3h). A marker for the $M$ phase, 
a
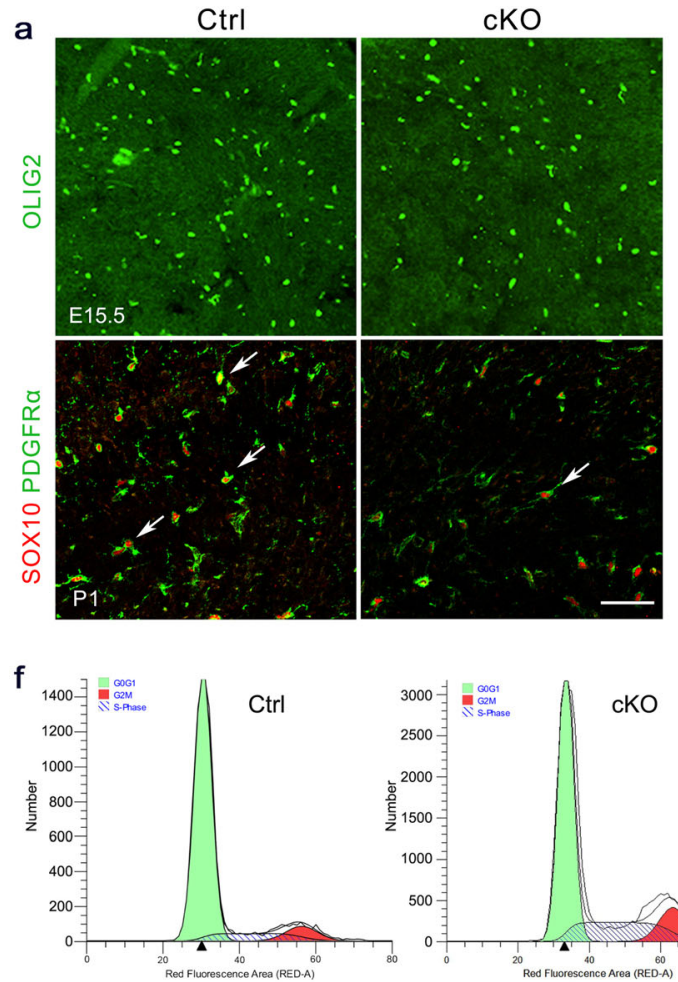

i

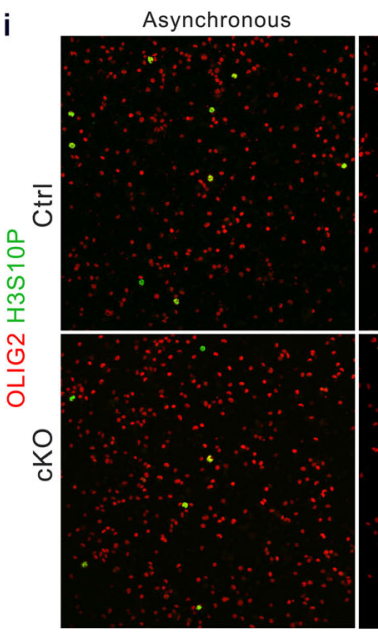

b
C
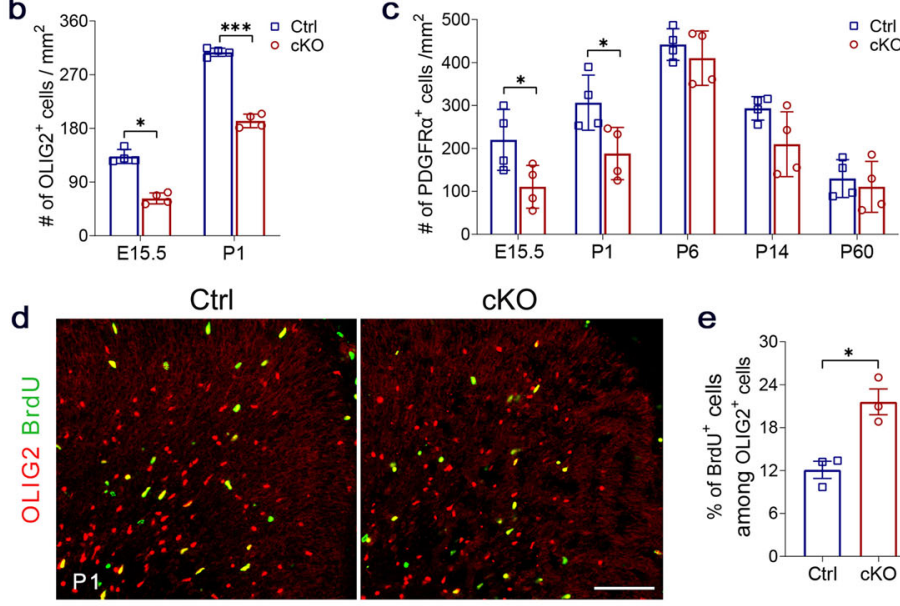

$\mathrm{cKO}$

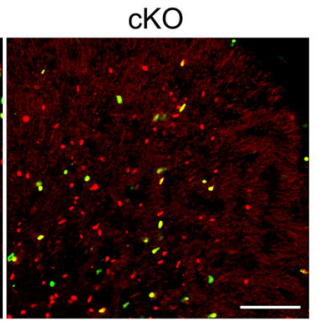

e

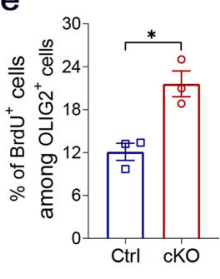

g

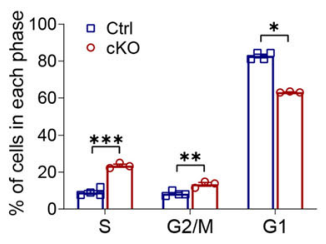

h

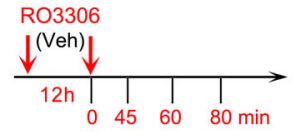

(A)

$45 \min$
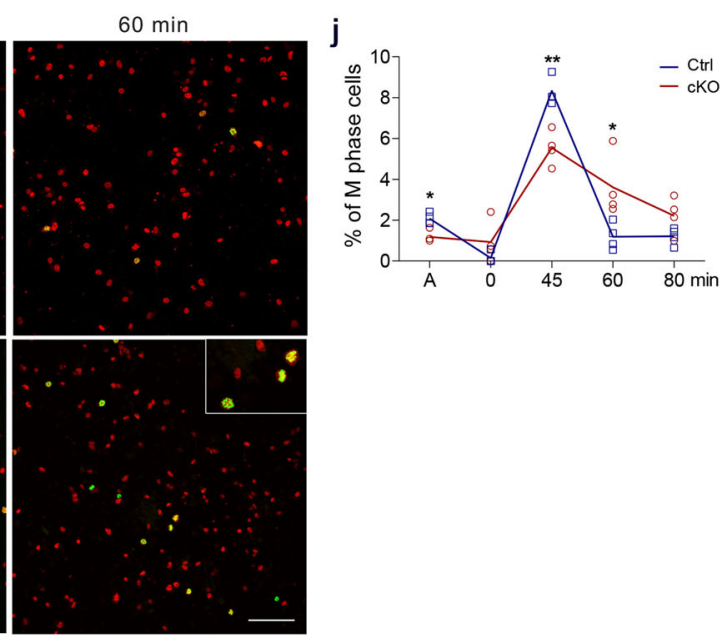

Fig. 3 Proliferation and cell-cycle progression are defective in Tet1 cKO OPCs. a Representative images of OLIG2 staining for embryonic day 15.5 (E15.5) and SOX10/PDGFR $\alpha$ staining for postnatal day 1 (P1) control and Tet1 cKO cortex. Scale bar, $100 \mu \mathrm{m}$. b Quantification of OLIG2+ cells in cortex from E15.5 and P1 control and Tet1 cKO mice. Data were Means \pm SEM ( $n=4$ animals per group). E15.5: ${ }^{*}$, Mann-Whitney U-test, $z=-2.309, p=0.021$ compared to control;

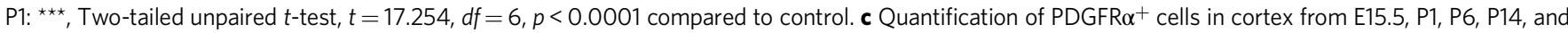
P60 control and Tet1 cKO mice. Data were Means \pm SEM ( $n=4$ animals per group). Two-tailed unpaired $t$-test, E15.5: ${ }^{\star}, t=2.519, d f=6, p=0.045 ; \mathrm{P} 1:{ }^{*}$, $t=2.682, d f=6, p=0.036 ; \mathrm{P} 60: t=0.522, d f=6, p=0.620$. Two-tailed unpaired separate variance estimation $t$-test, $\mathrm{P} 6: t=0.871, d f=4.823, p=0.425 ;$ P14: $t=2.085, d f=3.770, p=0.110$ compared to control. $\mathbf{d}$ Representative images of P1 control and Tet1 cKO cortex immunostained for BrdU and OLIG2. Scale bar, $100 \mu \mathrm{m}$. e Quantification of BrdU + cells within OLIG2+ OPC population in control and Tet1 cKO brains. Data were Means \pm SEM $(n=3$ animals per group). *, Two-tailed unpaired $t$-test, $t=-4.380, d f=4, p=0.012$ compared to control. $\mathbf{f}$ Representative flow cytometry traces of propidium iodide-stained OPCs from control and Tet1 cKO mice. $\mathbf{g}$ Quantification of the percentage of OPCs from control and Tet1 cKO mice in each phase of the cell cycle. Data were Means \pm SEM ( $n=4$ independent cultures for the control group and $n=3$ independent cultures for Tet1 cKO group). Two-tailed unpaired $t$-test, S: ${ }^{\star \star \star}$, $t=-10.556, d f=5, p=0.00013 ; \mathrm{G} 2 / \mathrm{M}:{ }^{\star}{ }^{\star}, t=-4.506, d f=5, p=0.006$; Mann-Whitney U-test, $\mathrm{G} 1:{ }^{*}, z=-2.141, p=0.032$ compared to control.

h Diagram showing cell cycle synchronization assay. RO3306, a CDK1 inhibitor, arrests the cell cycle at the G2 phase. Cultures were fixed for immunostaining at $\mathrm{A}$ point (Vehicle treatment for $12 \mathrm{~h}$ ), $\mathrm{O}$ (RO3306 treatment for $12 \mathrm{~h}$ ), and 45-, 60-, 80-min after RO3306 withdrawal. i Representative H3S1OP and OLIG2 double immunostaining for asynchronous and synchronized OPCs from control and Tet1 mutant. Cells were arrested at the G2/M phase with RO3306, $0 \mathrm{~h}$, and released with fresh medium for 45- and 60-min. Enlarged inserts indicate H3S10P+ metaphase nuclei. Scale bar, $100 \mu \mathrm{m}$. $\mathbf{j}$ Quantification of the percentage of $\mathrm{H3S1OP}+$ metaphase cells among OLIG2 ${ }^{+}$cells in asynchronous (A), arrested ( $\mathrm{h}$ h), and released control and Tet7-mutant OPCs. Data were Means \pm SEM ( $n=3$ independent experiments for control group at $45 \mathrm{~min}, n=4$ independent experiments for control at other time points and for Tet $1 \mathrm{cKO}$ group). Mann-Whitney U-test, $A:{ }^{\star}, z=-2.337, p=0.019 ; 0$ min: $\mathrm{ns}, z=-1.692, d f=6, p=0.091$; Two-tailed unpaired $t$-test: 45 min: ${ }^{\star \star}, t=4.469, d f=5$, $p=0.0066 ; 60$ min: ${ }^{\star}, t=2.897, d f=6, p=0.0275 ; 80 \mathrm{~min}: \mathrm{ns}, t=1.971, d f=6, p=0.0962$. 
phosphorylated histone $\mathrm{H} 3$ serine $10(\mathrm{H} 3 \mathrm{~S} 10 \mathrm{P})$, was used for immunostaining. In control OPCs, the percentage of $\mathrm{H}_{3} \mathrm{~S}_{10} \mathrm{P}^{+}$ cells among OLIG2 ${ }^{+}$cells peaked at $45 \mathrm{~min}$ post-release, indicating that most cells had progressed into the early stages of mitosis (Fig. 3i, j). In contrast, less Tet1 cKO OPCs were positive for $\mathrm{H} 3 \mathrm{~S} 10 \mathrm{P}$ at this time point. At $60 \mathrm{~min}$ post-release, control cells had progressed into anaphase as most H3S10P staining disappeared in $\mathrm{OLIG}_{2}{ }^{+}$cells. In the case of Tet $1 \mathrm{cKO}$ OPCs, we find that there is a delay in M-phase entry and withdrawal after cell cycle release (Fig. 3i, j). Thus, these results suggest that Tet 1 deletion results in a slower cell-cycle progression in OPCs, specifically during the G2-M transition, which likely leads to the observed reduction of OPC numbers in Tet 1 cKO animals.

In addition, we noted that Tet 1 deletion in Tet 1 cKO mice did not substantially alter the number of other neural cell types in the brain. Western blot and immunostaining with DCX, a marker for newly generated neurons; NeuN, a mature neuron marker; and ALDH1L1, an astrocyte marker, revealed comparable neuron and astrocyte pools between controls and Tet1 mutants (Supplementary Fig. $7 \mathrm{c}-\mathrm{g}$ ). Meanwhile, we validated that TET1 expression in astrocytes and neurons was not significantly decreased in Tet 1 cKO mice (Supplementary Fig. 7h, i). Taken together, our data suggest that the abnormal cell-cycle progression of OPCs and delayed OPC differentiation contribute to the reduced OL numbers and hypomyelination in juvenile Tet1-deficient mice.

TET1 regulates the transition from OPCs to OLs. To determine if defects in OL differentiation caused by TET1 deletion are cellautonomous, we isolated primary OPCs from the neonatal cortices of control and Tet 1 cKO pups and then treated them with T3 to induce differentiation. Immunostaining results showed that the percentage of $\mathrm{CNP}^{+}$and $\mathrm{MBP}^{+}$cells among OLIG2 ${ }^{+}$cells in Tet1-deficient OPCs were significantly decreased when compared with control OPCs at 3 DIV (day in vitro) and 5 DIV (Fig. 4a-c), suggesting that Tet1-depleted OPCs are intrinsically reduced in their differentiation capacity.

Since the impaired myelination in Tet $1 \mathrm{cKO}$ mice may result from the downsized OPC pool, to further confirm the role of TET1 in OL differentiation after birth, we bred Tet $1^{\text {flox/flox }}$ mice with NG2-CreER line $e^{35}$, an OPC-specific tamoxifen-inducible Cre line to generate Tet $1^{\text {flox/flox; }}$ NG2-CreER (Tet1 OPC-iKO) animals. The Tet1 OPC-iKO mice were treated daily with tamoxifen from P2 through P5 to induce Tet1 deletion (Fig. 4d) and double immunostaining confirmed TET1 loss in SOX10 ${ }^{+}$cells (Fig. 4e, f). Heterozygous littermates ( $\mathrm{Tet} \mathrm{1}^{\mathrm{flox} /+}$; NG2-CreER) were served as controls. In the P7 corpus callosum, more $\mathrm{PDGFRa}^{+} / \mathrm{Ki}^{6} 7^{+}$cells and less $\mathrm{MBP}^{+}$cells were observed in Tet1 OPC-iKO mice (Fig. $4 \mathrm{~g}-\mathrm{j}$ ). Moreover, a reduction in $\mathrm{CC1}^{+}$OLs and MBP intensity was observed in corpus callosum from P14 Tet1 OPC-iKO mice (Fig. $4 \mathrm{k}, 1)$. These results indicate that TET1 is required for the transition from OPCs to OLs.

In Tet1 cKO mice, wherein Tet1 is deleted in the Olig1-Cre expressing early precursors such as pri-OPC from the embryonic stages, we observed a decrease in the number of OPCs, suggesting that TET1 regulates the transition of OPCs from the pri-OPC state. However, in Tet1-iKO mice, wherein NG2-CreER is expressed in the committed OPCs, we observed a defect in OPC differentiation and a corresponding increase in undifferentiated OPCs, suggesting that TET1 deletion impairs OPC differentiation into mature OLs and maintains them in the OPC state. Thus, TET1 is involved in the early specification and later differentiation, producing stage-specific effects on OPC numbers.

We further performed the PPI test in Tet1-iKO mice at P42, which were treated daily with tamoxifen from P2 through P7 to induce Tet1 deletion in NG2 ${ }^{+}$OPCs. Similar to Tet1 cKO mice, the startle response was normal in Tet1-iKO mice, but the percentage of PPI was significantly attenuated (Supplementary Fig. 8a, b). These observations suggest that Tet 1 ablation in OL lineage cells leads to behavioral deficiency with impaired sensorimotor gating ability.

To further assess if TET1 deletion alters OPC fate or differentiation in adult mice, we used R26-EYFP reporter mice to test OL lineage progression in Tet 1 -iKO mice (Tet $1^{\text {flox/flox; }}$; NG2-CreER; R26-EYFP). We performed tamoxifen-mediated deletion at P30 in NG2-CreER Tet1-iKO; R26-EYFP mice and analyzed the GFP reporter positive Tet1-iKO cells at P60. We did not detect any significant alteration in the number of OPCs $\left(\mathrm{PDGFPa}^{+}\right)$and mature OLs $\left(\mathrm{CCl}^{+}\right)$in Tet1-iKO mice (Supplementary Fig. 8c-f). Thus, these data suggest that Tet1 ablation did not change OPC fate or differentiation in adult mice.

Efficient remyelination requires TET1 function. Given the critical role of TET1 in early OL development, we reasoned that TET1 should also be required in the adult brain for remyelination after an injury that results in demyelination. We induced demyelinated lesions in the corpus callosum via stereotaxic guided lysolecithin (LPC) injections (Fig. 5a). LPC induces rapid myelin breakdown followed by myelin regeneration through an OPC recruitment phase at 7 days post-lesion $(7 \mathrm{dpl})$ induction and a remyelination phase at $14 \mathrm{dpl}$. To evaluate the role of TET1

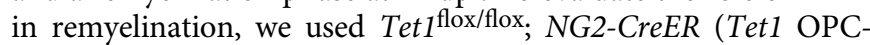
iKO) animals mentioned above. To induce recombination in adult mice, 8-week-old Tet1 OPC-iKO mice were injected daily with tamoxifen for 8 days, starting 3 days prior to LPC injection in the corpus callosum (Fig. 5b). Brains were harvested at 7, 14, and $21 \mathrm{dpl}$ from Tet1 OPC-iKO mice and controls. Compared to control mice injected with vehicle, $\mathrm{TET}^{+}$cell numbers were increased substantially in the lesion site at $7 \mathrm{dpl}$ (Fig. $5 \mathrm{c}$, d). In particular, the expression levels of TET1 in OLIG2 ${ }^{+}$cells were higher after LPC treatment (Fig. 5c, d). In Tet1 OPC-iKO mice, immunostaining showed $\sim 97 \%$ OLIG2 ${ }^{+}$cells lack TET1 expression at $7 \mathrm{dpl}$, indicating the efficient deletion of Tet 1 by NG2-Cre (Fig. 5c-e). Notably, TET1 ${ }^{+}$OLIG2 ${ }^{+}$OL lineage cells increased in the lesion at $7 \mathrm{dpl}$, while TET1 expression was detected in a subset of IBA1 ${ }^{+}$microglia and $\mathrm{NESTIN}^{+}$cells, but not in GFAP ${ }^{+}$ astrocytes (Supplementary Fig. 8g).

To determine the extent of remyelination, we examined the expression of OPC markers and myelin-related genes. Loss of Tet1 did not appear to impair the recruitment of PDGFRa ${ }^{+}$ OPCs, and the numbers of OPCs in the lesions were comparable between control and Tet1 OPC-iKO mice during the recruitment phase at $7 \mathrm{dpl}$ (Fig. $5 \mathrm{f}, \mathrm{g}$ ). In contrast, there were significantly fewer GST-pi ${ }^{+}$differentiating OLs in the lesion site during the remyelination phase at 14 and $21 \mathrm{dpl}$ in Tet 1 OPC-iKO mice relative to controls (Fig. $5 \mathrm{f}, \mathrm{h}$ ). Consistent with a reduction in the number of differentiating OLs, MBP was also reduced in Tet1iKO lesions compared to those of controls at $21 \mathrm{dpl}$ (Fig. 5i). Notably, far fewer remyelinated axons were detected in the lesions of Tet1-iKO mice than controls at $28 \mathrm{dpl}$ examined by EM (Fig. 5j, k). Furthermore, the thicknesses of newly generated myelin sheaths around axons were significantly reduced in Tet1iKO mutants (Fig. 5l). These observations indicate that TET1 is required for the proper remyelination in the context of white matter injury.

Transcriptome alterations and a genome-wide decrease of $5 \mathrm{hmC}$ in Tet1-ablated OPCs. To investigate the molecular underpinnings of the observed defects in early OL development, we compared the RNA transcriptomes of OPCs cultured from 

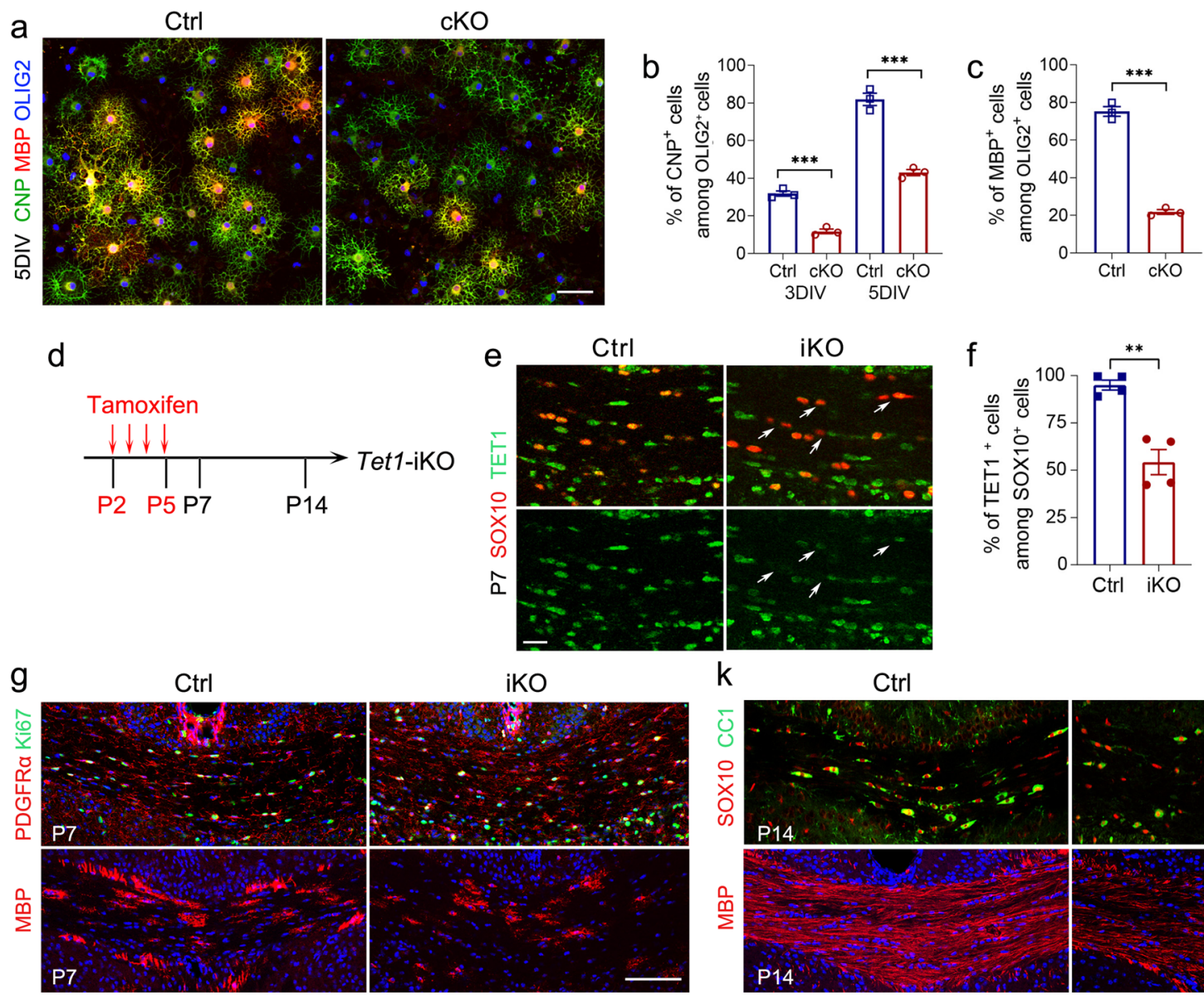

$\mathrm{k}$
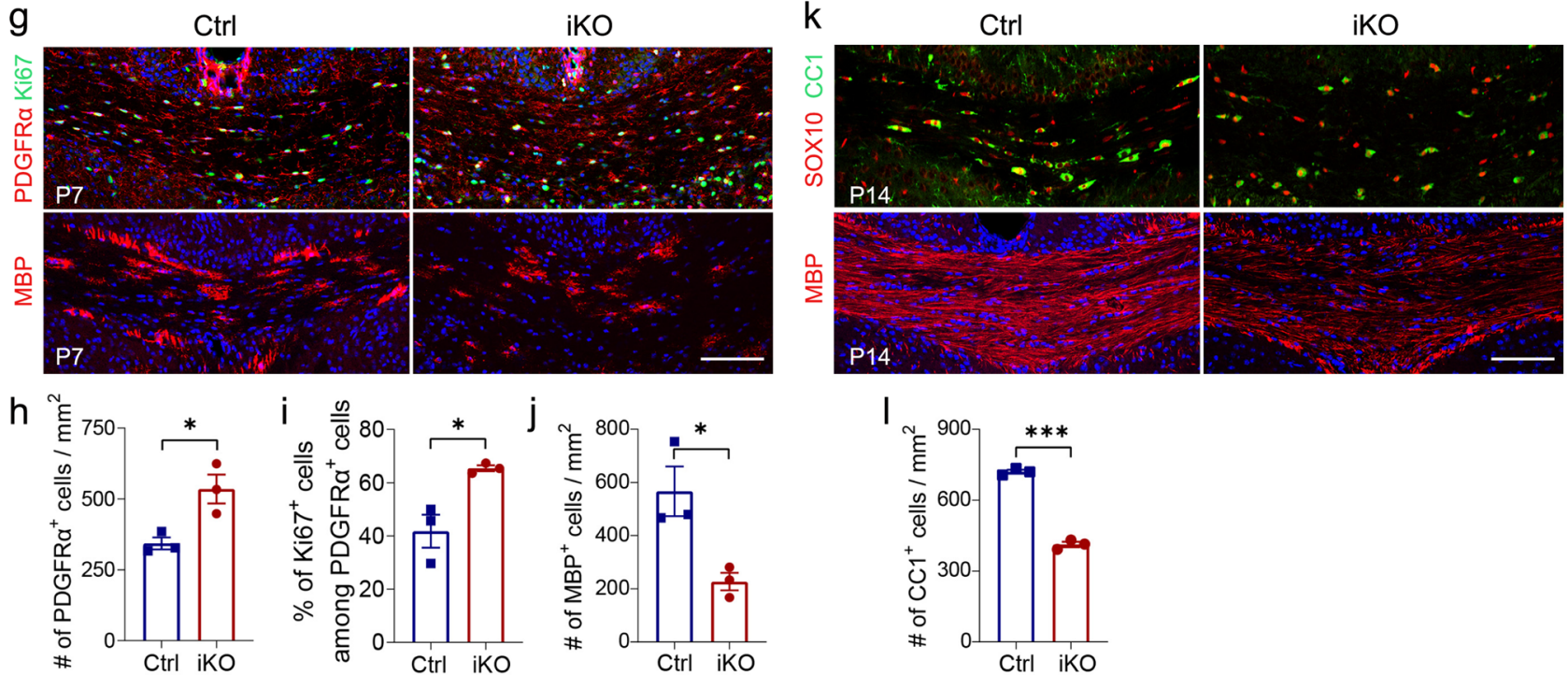

Fig. 4 OPC differentiation is impaired in Tet1 OPC-iKO mice. a Representative images of OL cultures from control and Tet1 cKO mice immunostained with CNPase, MBP, and OLIG2 at 5 days in vitro ( 5 DIV). Scale bar, $50 \mu \mathrm{m}$. b Quantification of CNPase ${ }^{+}$cells among OLIG2 ${ }^{+}$cells in the cultures from control or Tet1 cKO mice at 3 or 5 DIV. Data were Means \pm SEM ( $n=3$ of independent cultures in each group). Two-tailed unpaired $t$-test, 3 DIV: ${ }^{\star \star \star}, t=10.716$, $d f=4, p=0.00043 ; 5 \mathrm{DIV}:{ }^{\star \star \star}, t=10.603, d f=4, p=0.000448$ compared to control. c Quantification of MBP+ cells among OLIG2+ cells in the cultures from control or Tet1 cKO mice at 5 DIV. Data were Means \pm SEM ( $n=3$ of independent cultures in each group). Two-tailed unpaired $t$-test, ${ }^{\star \star \star}, t=18.644$, $d f=4, p=0.000049$ compared to control. d Diagram showing Tamoxifen administration to induce the Cre recombination in Tet1 OPC-iKO (Tet1 flox/flox; NG2-CreER) mice. e Representative images of P7 control and Tet1-iKO mice corpus callosum stained for TET1 and SOX10. Arrows indicate SOX10 ${ }^{+}$cells that show reduced levels of TET1 in Tet1-iKO image. Scale bar, $20 \mu \mathrm{m}$. f Percentages of TET1 ${ }^{+}$cells among SOX10 ${ }^{+}$oligodendrocytes in P7 corpus callosum. Data were Means \pm SEM ( $n=4$ animals per group). Two-tailed unpaired separate variance estimation $t$-test, ${ }^{* *}, t=5.707, d f=3.933, p=0.005$ compared to control. $\mathbf{g}$ Representative images of control and Tet1 OPC-iKO P7 corpus callosum stained for PDGFR $\alpha / \mathrm{Ki} 67$ or MBP. Scale bar, $100 \mu \mathrm{m}$. $\mathbf{h}-\mathbf{j}$ Quantification of the density of PDGFR $\alpha^{+}$cells $(\mathbf{h})$, the percentage of Ki67+ cells among PDGFR $\alpha^{+}$cells (i), and the density of MBP ${ }^{+}$cells at P7 (j). Data were presented as Means \pm SEM ( $n=3$ animals per group). Two-tailed unpaired $t$-test, $\mathbf{h}:{ }^{\star}, t=-3.489, d f=4, p=0.025$ compared to control. i: ${ }^{\text {, }}$ $t=-3.757, d f=4, p=0.020$ compared to control. $\mathbf{j}:{ }^{\star}, t=3.426, d f=4, p=0.027$ compared to control. $\mathbf{k}$ Representative images of control and Tet1 OPCiKO P14 corpus callosum stained for CC1/SOX10 and MBP. Scale bar, $100 \mu \mathrm{m}$. I Quantification of the density of CC1+ cells at P14. Data were presented as Means $\pm \operatorname{SEM}\left(n=3\right.$ animals per group). Two-tailed unpaired $t$-test, ${ }^{\star \star \star}, t=22.136, d f=4, p=0.000025$ compared to control.

control and Tet1 cKO neonates. There were $\sim 1880$ genes downregulated and 881 genes upregulated in Tet1 mutants compared with controls (FDR $<0.05, \log _{2}>1$ or $<-1$ ) (Supplementary Table 2), suggesting that the predominant effect of Tet 1 was transcriptional activation. As indicated by GSEA, among the top downregulated TET 1 targets were those pertinent to cell division, extracellular matrix, and OL differentiation (Fig. 6a-d), which are in consistent with the abnormal cell cycle and deficient myelin formation in Tet1 mutants. In contrast, GO terms associated with the mitochondria gene module and immune-related functions were upregulated in Tet1 cKO OPCs (Fig. 6a, b, e, f). The observation that TET1-activated genes are related to OL differentiation may reflect a cell-type-specific transcriptional regulation for TET1 in OL differentiation. Quantitative PCR confirmed 
a

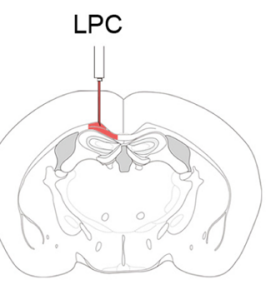

b

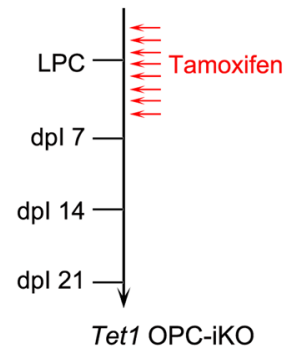

C



$\mathrm{iKO}+\mathrm{LPC}$

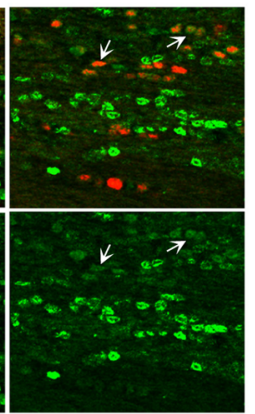

d

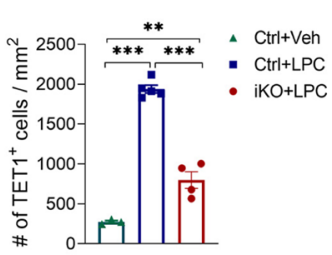

e

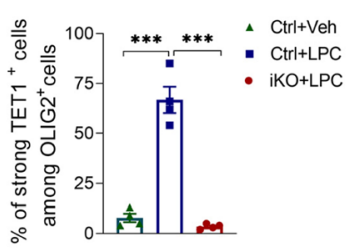

f
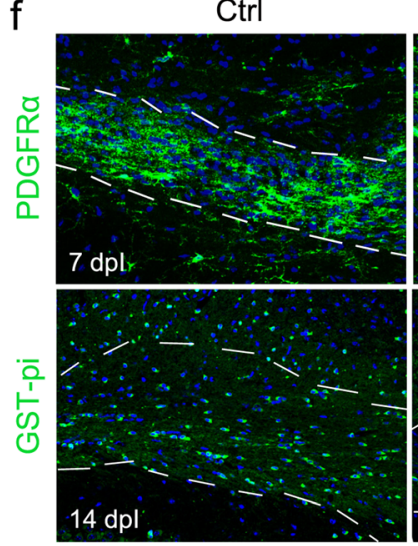
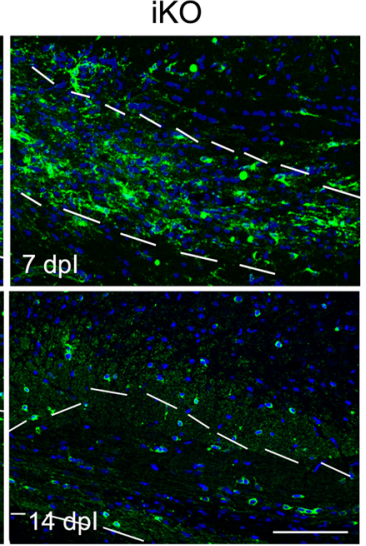

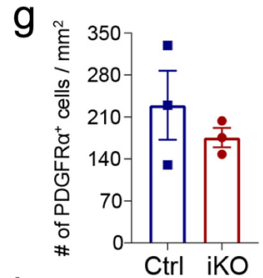

$\mathrm{h}$

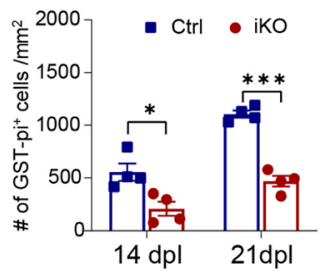

i Ctrl-contralateral

Ctrl-LPC

iKO-LPC
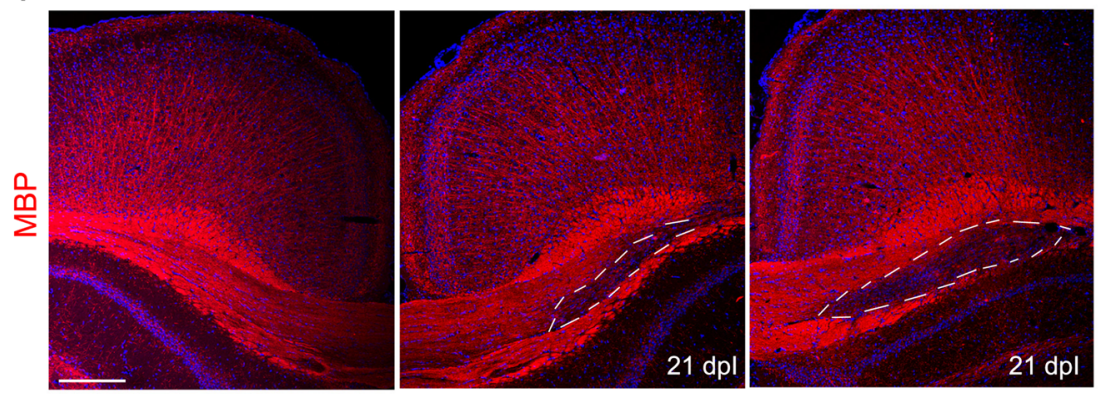

j
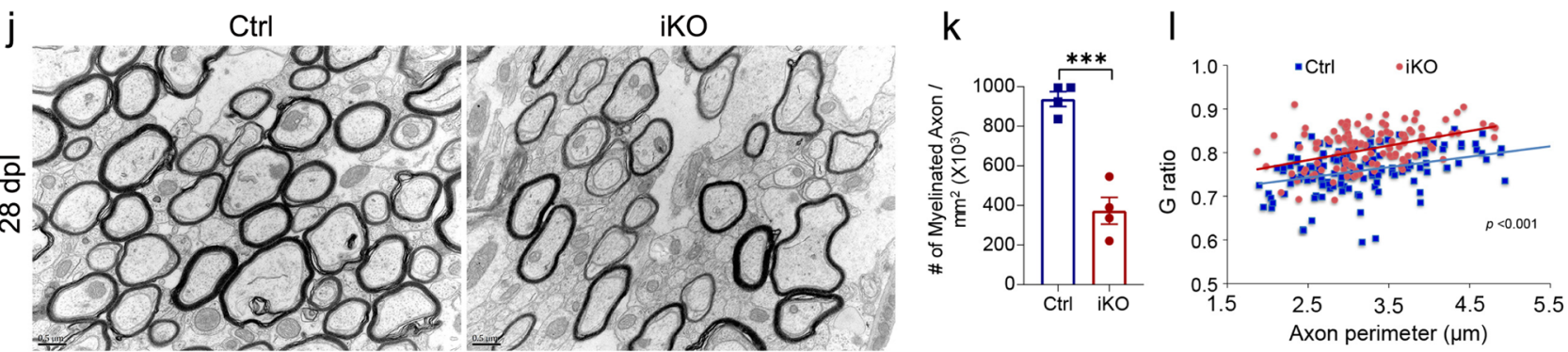

representative gene expression changes associated with these gene set enrichments in the RNA-seq data (Fig. 6g-i). Specifically, OL differentiation and myelination-associated genes Mbp, Plp1, Myrf, Enpp2, Cnp, Cldn11, Ugt8a, Kif11, and Bcas1 were markedly downregulated in Tet1-deficient OPCs (Fig. 6g) as were genes involved in cell-cycle regulation, e.g., Ccnb1, Cdc25b, and Cdc25c (Fig. $6 \mathrm{~h}$ and Supplementary Fig. $6 \mathrm{j}, \mathrm{k}$ ). The transcriptome landscape alterations in Tet1 cKO OPCs were in line with the observations that Tet1 depletion led to cell-cycle progression defects and hypomyelination phenotypes.

Since TET1 mediates DNA hydroxymethylation/demethylation, we next tested the level of $5 \mathrm{hmC}$ in OLs from Tet 1 mutants.
In $\mathrm{P} 27$ brain sections, immunostaining of $5 \mathrm{hmC}$ simultaneously with the OL marker CC1 revealed a striking reduction in $5 \mathrm{hmC}$ intensity in Tet1 cKO OLs (Fig. 7a, b), which strongly suggested that $5 \mathrm{hmC}$ is involved in TET1-mediated regulation of OL differentiation. To further compare the genome-wide $5 \mathrm{hmC}$ distributions, we performed hMeDIP-seq in OPC cultures from controls and Tet1 mutants. Tet1 cKO OPCs showed a dramatic reduction in $5 \mathrm{hmC}$ peak signals compared to controls (Supplementary Fig. 9a). In both groups, most $5 \mathrm{hmC}$ peaks resided in intergenic regions; less than $40 \%$ of peaks were within gene bodies of annotated RefSeq genes (Supplementary Fig. 9b). This is different from the distribution pattern in mouse embryonic stem 
Fig. 5 Impaired CNS remyelination in Tet1 OPC-iKO mice. a Diagram of the brain showing the lysolecithin (LPC) injection site. b Schedule for Tamoxifen administration and LPC injection in Tet1 flox/flox; NG2CreER mice (Tet1 OPC-iKO). c Representative images of TET1 immunostaining in the corpus callosum of non-lesion vehicle injection region of control mice ( Ctrl + Veh), LPC-induced lesion region of control mice (Ctrl + LPC), and Tet7-iKO mice (iKO + LPC) at 7 days post-lesion ( $7 \mathrm{dpl}$ ). Arrows indicate OLIG2+ cells. Note the upregulated TET1 expression in Ctrl + LPC mice, but the decreased TET1 expression in iKO + LPC mice, indicating the effective ablation of TET1 in Tet1-iKO mice. Scale bar, $50 \mu \mathrm{m}$. d Quantification of TET1+ cell density in LPC lesion sites at 7 dpl. Data were presented as Means \pm SEM ( $n=3$ animals for Ctrl + Veh group, $n=5$ animals for Ctrl + LPC group, $n=4$ animals for iKO + LPC group). One-way ANOVA, $F_{(2,9)}=146.116, p<0.00001$. Tukey's multiple comparisons test: ${ }^{\star \star \star}, \mathrm{Ctrl}+$ Veh vs. Ctrl $+\mathrm{LPC}: q=22.68, d f=9, p<0.0001,{ }^{\star \star}$, Ctrl + Veh vs. iKO + LPC: $q=6.842, d f=9, p=0.0024,{ }^{\star \star \star}$, Ctrl + LPC vs. iKO + LPC: $q=16.90, d f=9, p<0.0001$. e Quantification of the percentages of strong TET1 + among OLIG2 ${ }^{+}$cells in LPC lesion sites at $7 \mathrm{dpl}$. Data were presented as Means \pm SEM ( $n=4$ animals for each group). One-way ANOVA, $F_{(2,9)}=69.852, p<0.000003$. Tukey's multiple comparisons test: ${ }^{\star \star \star}, \mathrm{Ctrl}+$ Veh vs. Ctrl + LPC: $q=14.57, d f=9, p<0.0001, \mathrm{~ns}, \mathrm{Ctrl}+\mathrm{Veh}$ vs. iKO + LPC: $q=0.1852, d f=9, p=0.9906, C t r l+$ LPC vs. iKO + LPC: ${ }^{\star \star \star}, q=14.38, d f=9, p<0.0001$. f Representative images of lesion regions from control and Tet1-iKO mutants at $7 \mathrm{dpl}$ and $14 \mathrm{dpl}$. Samples were immunolabeled for PDGFR $\alpha$ and GST-pi, respectively. Dashed line indicates the border of the lesion site. Scale bars, $100 \mu \mathrm{m}$. $\mathbf{g}$ Quantification of PDGFR $\alpha^{+}$OPCs in LPC lesion sites at $7 \mathrm{dpl}$. Data were Means \pm SEM ( $n=3$ animals in each group). Two-tailed unpaired $t$-test, $t=0.905, d f=4, p=0.416$ compared to control. $\mathbf{h}$ Quantification of GST-pi ${ }^{+}$OLs in LPC lesion sites at 14 and $21 \mathrm{dpl}$. Data were Means \pm SEM ( $n=4$ animals in each group). Two-tailed unpaired $t$-test, $14 \mathrm{dpl}:{ }^{*}, t=3.241, d f=6, p=0.018 ; 21 \mathrm{dpl}:{ }^{\star \star \star}, t=10.281, d f=6, p=0.000049$ compared to control. i Contralateral side and LPC lesion regions from control and Tet1-iKO corpus callosum at 21 dpl. Samples were immunostained for MBP. Scale bar, $200 \mu \mathrm{m}$. j Representative images of electron micrographs of lesion regions from control and Tet7-iKO mutants at $28 \mathrm{dpl}$. Scar bar, $0.5 \mu \mathrm{m}$. $\mathbf{k}$ The number of myelinated axons in lesion regions from control and Tet7-iKO mutants at $28 \mathrm{dpl}$. Data were Means \pm SEM ( $n=4$ slides from three animals per group). Two-tailed unpaired $t$-test, ${ }^{\star \star \star}, t=7.294, d f=6, p=0.00034$ compared to control. I $\mathrm{G}$ ratios vs. axonal perimeters in lesion regions from control and Tet1-iKO mutants at $28 \mathrm{dpl}$. Friedman $M$ test, $\chi^{2}=47.641, d f=1, p<0.0001$. $p_{\text {between group }}<0.001$ ( $>130$ myelinating axon counts from three animals each genotype).

cells $^{18}$ and neurons ${ }^{36}$. After plotting the distribution of $5 \mathrm{hmC}$ peaks over RefSeq genes, we found that $5 \mathrm{hmC}$ was reduced near the TSS and transcription terminal site (TTS) in control OPCs and that Tet 1 depletion caused reductions of $5 \mathrm{hmC}$, especially in intragenic regions, promoter regions, and TTS regions (Fig. 7c and Supplementary Fig. 9b). Heatmap clustering of the $5 \mathrm{hmC}$ peak distributions 5-kb upstream and downstream of TSSs revealed five groups; levels of $5 \mathrm{hmC}$ signals were lower in all five groups in Tet $1 \mathrm{cKO}$ samples than in the control samples (Fig. 7d). Further analysis showed that most differentially hydroxymethylated regions also had a low CpG density of less than $1 \mathrm{CpG}$ per 100 bp (Supplementary Fig. 9c).

We next examined the correlation between hydroxymethylation and gene expression. By integrating RNA-seq data with hMeDIP-seq data, we observed that among the genes that had lower hydroxymethylation in gene body regions in the Tet $1 \mathrm{cKO}$ mice than in controls, $12.83 \%$ was downregulated (1026 of 7998 genes) and $4.89 \%$ was upregulated (391 of 7998 genes) (Supplementary Fig. 9d). The percentages were comparable in promoter regions that were differentially hydroxymethylated with $13.46 \%$ of genes downregulated and $6.42 \%$ upregulated genes (Supplementary Fig. 9e). These observations indicate that DNA hydroxymethylation is positively correlated with gene expression in OLs.

Among the genes that showed both downregulated mRNA expression and decreased gene body $5 \mathrm{hmC}$ levels in Tet $1 \mathrm{cKO}$ mice, GO analysis revealed that a majority of them are associated with OL differentiation, cell proliferation, and extracellular matrix (Fig. 7e, f). For example, Mbp, Mobp, and Cnp are myelin-related genes; Tcf7L2, Myrf, and Enpp2/6 are involved in the regulation of OL differentiation in a stagespecific manner within different transcriptional circuitries ${ }^{37,38}$. Snapshots of $5 \mathrm{hmC}$ profiles of representative myelination genes and cell division genes showed reduced $5 \mathrm{hmC}$ levels in Tet 1 cKO group (Fig. $7 \mathrm{~g}$ and Supplementary Fig. 9f, g). To further test the genome-wide $5 \mathrm{hmC}$ landscape changes during OPC-OL transition, we compared hMeDIP-seq data in OLs with that in OPCs. Interestingly, we find increased $5 \mathrm{hmC}$ intensity in OL compared to OPC (Supplementary Fig. 10), which indicates that the changes in $5 \mathrm{hmC}$ epigenetic marks might contribute to OPC-OL transition. Together, these results are highly in consistent with the hypomyelination phenotypes in Tet1 cKO mice and indicate the significance of TET1-5hmC mechanisms in OL homeostasis.

To further identify potential TET1 direct targets, we performed Cut \& Run assays ${ }^{39}$ for high-resolution mapping of TET1 DNA binding sites. Most TET1 binding sites overlapped with $5 \mathrm{hmC}$ modified regions (Fig. 8a), suggesting that TET1 directly binds to these target genes and facilitates hydroxymethylation in the regulatory elements. GO analysis for TET1 and $5 \mathrm{hmC}$ overlapped targets in OPCs revealed genes associated with OL differentiation, calcium ion transport, and cell proliferation (Fig. 8b). Furthermore, TET1 binding profiles with TET1 antibody in representative genes were in accordance with $5 \mathrm{hmC}$ peaks, and associated with the activating histone mark H3K27ac (Fig. 8c), indicating a transcriptional activation role of TET1 in addition to its DNA methylcytosine dioxygenase activity in the regulation of gene transcription.

Impaired calcium transport leads to differentiation defects in OPC cultures from Tet1 cKO mice. When searching for TET1$5 \mathrm{hmC}$ regulated factors that may involve in $\mathrm{OL}$ development and homeostasis, we noticed that there was a cluster of calcium transporter genes among the downregulated and hypohydroxymethylated genes in Tet $1 \mathrm{cKO}$ group (Figs. 6a, b and 7e, $\mathrm{f}, \mathrm{h}, \mathrm{i})$. The decreased expression of these genes in Tet $1 \mathrm{cKO}$ mice was confirmed by qRT-PCR assays (Fig. 7j). CACNA1a, CACNA1c, CACNA2d1, CACNB4, and CACNG5 are plasma membrane voltage-operated $\mathrm{Ca}^{2+}$ channels (VOCCs) that are expressed in OPCs and contribute to calcium dynamics in these cells ${ }^{22,40}$. In particular, calcium influx mediated by CACNA1c, also known as $\mathrm{Ca}_{\mathrm{v}} 1.2$, is required for OL differentiation ${ }^{41,42}$. Another target gene Itpr2, which encodes a type $2 \mathrm{IP}_{3}$ receptor, localized to the ER and expressed exclusively in postmitotic OLs ${ }^{43,44}$, also showed decreased mRNA expression in OPCs from Tet1 cKO mice compared to controls (Fig. 7j). These data indicate that TET1-5hmC targets calcium transport genes and may regulate calcium dynamics in OLs. Similar to a recent observation ${ }^{23}$, we also observed several members of the solute carrier ( $S l c)$ gene family as TET1-5hmC targets, e.g., Slc24a2, Slc8a1, Slc12a2, and Slc7a14 (Fig. 7h-j and Supplementary Fig. 9g). This result indicates that TET1-5hmC may control OL function through multiple targets.

To evaluate the intracellular $\mathrm{Ca}^{2+}$ concentration $\left(\left[\mathrm{Ca}^{2+}\right]_{\mathrm{i}}\right)$ fluctuation in OPC culture, a Fluo4-based $\mathrm{Ca}^{2+}$-imaging approach 



Fig. 6 Lack of Tet1 alters the transcriptome profiles in OPCs. a Heatmap of RNA-seq data from purified OPCs shows categories of differentially expressed genes between control and Tet1 cKO mice. Each genotype was repeated once. b GSEA analysis of the most differentially regulated genes in OPC cultures from Tet1 mutant and control mice. c-f GSEA plots of genes involved in oligodendrocyte differentiation (c), cell division (d), mitochondria genes (e), and chemokine signaling pathway genes (f) in control and Tet7-mutant OPCs. g-i Quantitative real-time PCR of oligodendrocyte differentiation genes (g), genes involved in cell division and G2/M cell cycle regulation (h), and chemokine genes (i) in control and Tet7-mutant OPCs. Data were Means \pm SEM of transcript levels relative to control after normalization from $n=3$ independent experiments each performed in triplicate. $\mathbf{g}$ Two-tailed unpaired $t$-test. Bcas 1 : ${ }^{\star \star \star}, t=25.375, d f=4, p=0.000014 ; P l p:{ }^{\star \star}, t=6.214, d f=4, p=0.0034 ; C n p:{ }^{\star \star \star}, t=35.28, d f=4, p<0.0001 ; K i f 11:{ }^{\star \star \star}, t=18.50, d f=4, p=0.00005$ Ugt8a: ${ }^{\star \star \star}, t=56.64, d f=4, p<0.0001 ;$ Enpp2: ${ }^{\star \star \star}, t=74.57, d f=4, p<0.0001 ;$ Myrf: ${ }^{\star \star \star}, t=23.955, d f=4, p=0.000013 ; C l d n 11:{ }^{\star \star \star}, t=16.173, d f=4$, $p=0.000086 ; M b p:{ }^{\star \star \star}, t=33.299, d f=4, p=0.000005$. h Two-tailed unpaired $t$-test. Cdc25b: ${ }^{\star \star}, t=11.384, d f=4, p=0.000344 ; C d c 25 c:{ }^{\star \star \star}$, $t=25.527, d f=4, p=0.000014 ; C c n a 2:{ }^{\star \star \star}, t=12.123, d f=4, p=0.000266 ; C d k 19:{ }^{\star \star \star}, t=9.264, d f=4, p=0.0008 ; C c n g 2:{ }^{\star \star \star}, t=26.16, d f=4$, $p<0.0001 ;$ Ccnf: ${ }^{\star \star}, t=6.263, d f=4, p=0.0033 ;$ Ccnb1: ${ }^{\star \star \star}, t=47.51, d f=4, p<0.0001 ;$ Cdca3: ${ }^{\star \star \star}, t=17.992, d f=4, p=0.000056 . \mathbf{i}$ Two-tailed unpaired $t$-test. $C c 12:{ }^{\star \star \star}, t=47.22, d f=4, p<0.0001 ; C c 122:{ }^{\star \star \star}, t=-14.905, d f=4, p=0.000118 ; C c r 2:{ }^{\star \star}, t=-7.249, d f=4, p=0.00192 ; C x 3 c r 1:{ }^{\star \star}$, $t=7.773, d f=4, p=0.0015$.

was employed. ATP can mobilize $\mathrm{Ca}^{2+}$ from ER stores or trigger $\mathrm{Ca}^{2+}$ influx across the plasma membrane ${ }^{45,46}$. To first determine the intracellular calcium release, we used calcium-free aCSF to load Fluo4. In OPC cultures, the application of ATP induced a transient increase of $\left[\mathrm{Ca}^{2+}\right]_{\mathrm{i}}$ in both control and Tet1 cKO groups (Fig. 9a, b and Supplementary Movies 1 and 2). The amplitude of ATPinduced calcium rise was significantly higher in control OPCs than in Tet1-mutant OPCs (Fig. 9c). This result indicates a deficit of intracellular calcium mobilization in Tet1- depleted OPCs. Additionally, we compared the relative free $\mathrm{Ca}^{2+}$ level of internal stores between control and Tet1 cKO OPCs with mag-Fluo4-AM, a low $\mathrm{Ca}^{2+}$ affinity fluorescent indicator for the ER, as previously reported ${ }^{47}$. Living OPCs from both groups showed similar relative mag-Fluo4-AM fluorescence in the ER, as measured by spectrofluorometer (Supplementary Fig. 11a, b).
To further examine the extracellular calcium influx in Tet 1 cKO OPCs, we used Bay K 8644, an L-type calcium channel (L-VOCC) agonist ${ }^{48}$, to induce synchronous calcium transient in OPCs, which can be blocked by the specific L-VOCC inhibitor Verapamil (Supplementary Fig. 11c). In the mutant OPCs, $\left[\mathrm{Ca}^{2+}\right]_{\mathrm{i}}$ increase was of lower amplitude and the kinetics of onset were slower (Supplementary Fig. 11d, e), suggesting the attenuated function of membrane calcium channel in Tet1ablated OPCs.

To investigate the consequences of impaired calcium rise in Tet1-deficient OPCs, we examined cell differentiation after activating calcium signaling. Consistent with the results of high $\mathrm{K}^{+}$application $^{42}$, three consecutive pulses ( 5 min/each) daily with $10 \mu \mathrm{M}$ calcium channel agonist Bay K 8644 significantly promoted differentiation of OPCs and partially rescued the differentiation 
$a_{\text {P27 }}$
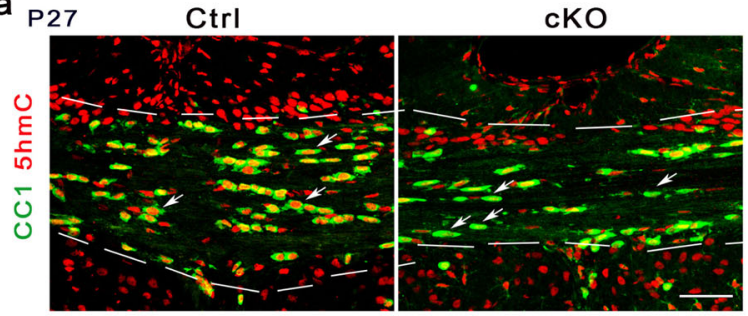

b

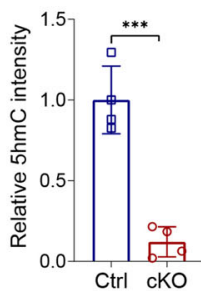

C

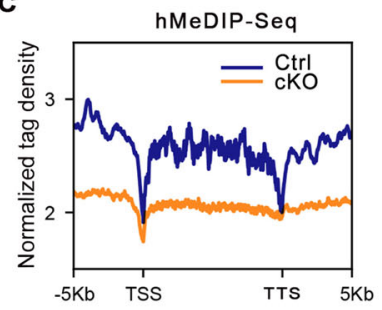

d
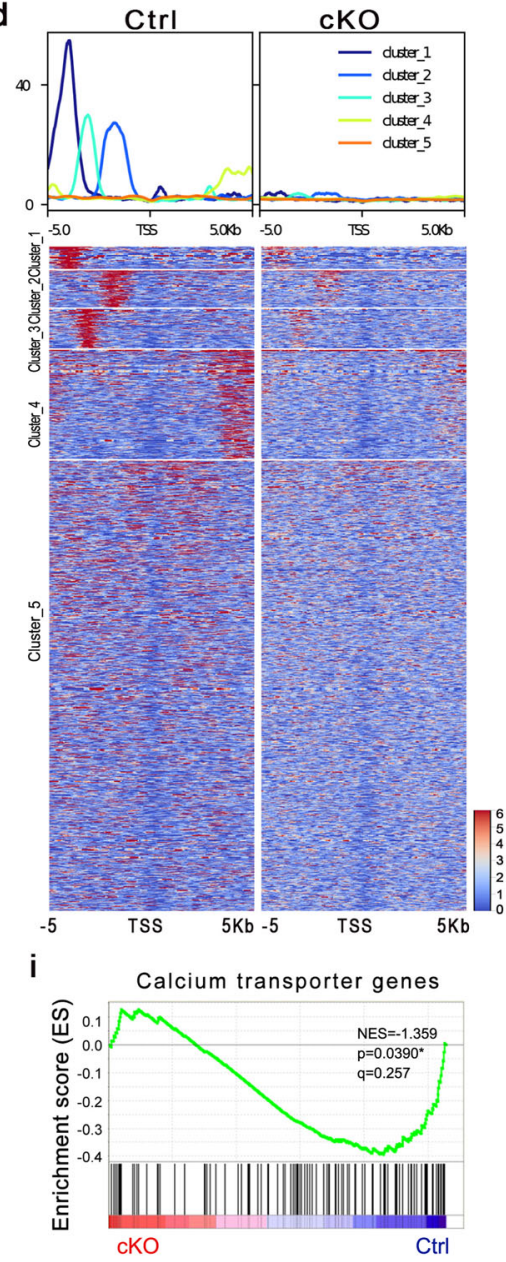

e Downregulated

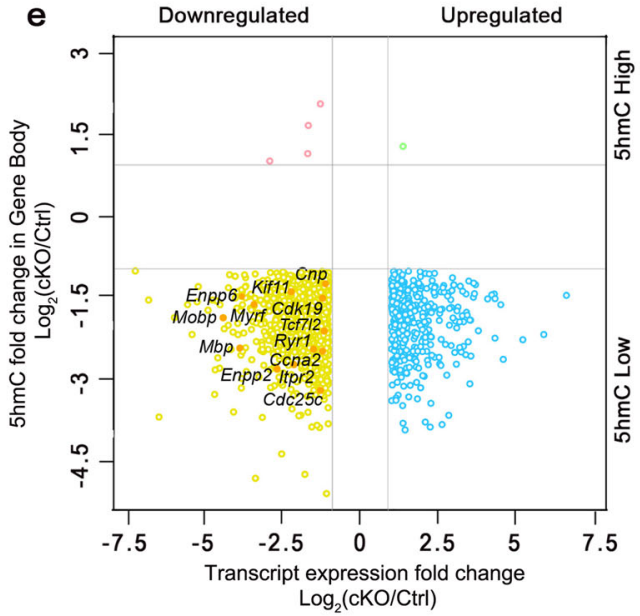

f GO analysis for downregulated and hypo-hydroxymethylated genes

$0 \quad 100200300400500600$

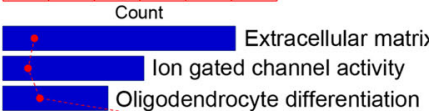
Oligodendrocyte differentiation Cell communication

Response to external stimulus Regulation of cell differentiation Calcium ion homeostasis Lipid transport Growth factor receptor binding - Ligand-gated ion channel activity b. Morphogenesis of branching structure Positive regulation of cell proliferation Positive regulation of cytosolic calcium - Positive regulation of cytosolic calcium
ion concentration

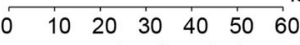
$-\log _{2}(p$-value $)$

g


h
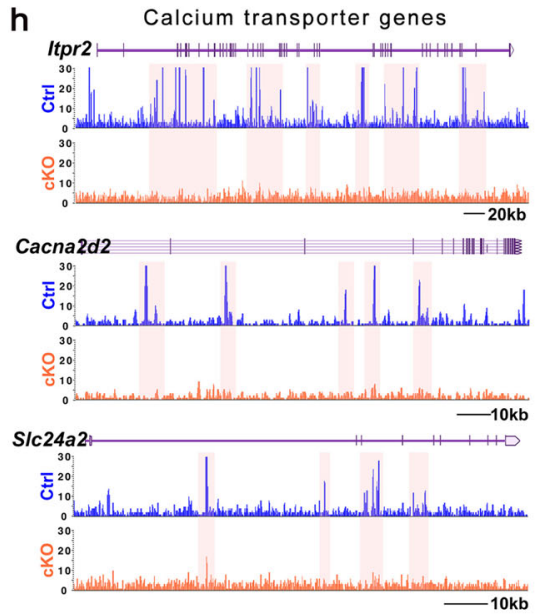

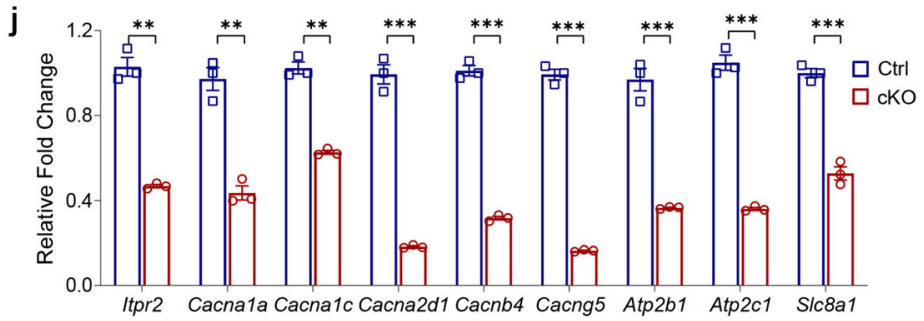

defects in Tet1-deficient OPCs as determined by qRT-PCR analysis of myelin genes and $\mathrm{MBP}^{+}$OL numbers (Supplementary Fig. 11f-h). These data indicate that TET1-modulated $\left[\mathrm{Ca}^{2+}\right]_{\mathrm{i}}$ rise play important roles in the OL differentiation process.

Ablation ITPR2, a modulator for calcium release from ER, inhibits OL differentiation. To further distinguish calcium signaling as TET1-5hmC target during OL differentiation, or the results of impaired differentiation in Tet $1 \mathrm{cKO}$ mice, we then tested the function of ITPR2, one of TET1-5hmC target calcium transport genes, in myelination. As a modulator for calcium release from ER, ITPR2 showed the highest expression in postmitotic newly formed OLs (OL-1DIV, PDGFR $\alpha^{-} / \mathrm{CNPase}^{+}$) (Fig. 9d and Supplementary Fig. 12a) as reported previously ${ }^{22,43,44}$. In vitro studies with RNAi methods revealed that transfection of siRNA against Itpr2 in normal OL cultures significantly reduced the expression of myelin genes and impaired OL differentiation (Fig. 9e-g and Supplementary Fig. 12b, c). Additionally, we tested the effect of adenophostin-A (Ada), a high-affinity agonist of ITPR $2^{49}$, on rescuing impaired Tet 1 cKO OPC calcium rise and differentiation in cultures. Daily application of Ada for 2 days in Tet1 cKO OPC cultures significantly increased the amplitude of 
Fig. 7 DNA hydroxymethylation of genes and transcript levels are correlated in oligodendrocytes from Tet1 cKO mice. a Representative images of $5 \mathrm{hmC}$ and CC1 immunostaining in the corpus callosum of P27 control and Tet1 cKO mice. Attenuated level of $5 \mathrm{hmC}$ in $\mathrm{CC}^{+}$cells in Tet1 mutant is indicated by arrows. Scale bar, $50 \mu \mathrm{m}$. b Quantification the fluorescence intensity of $5 \mathrm{hmC}$ staining in $\mathrm{CC}^{+}$cells from control and Tet1 cKO brains. Data were Means $\pm \operatorname{SEM}\left(n=4\right.$ animals per group). Two-tailed unpaired $t$-test, ${ }^{\star \star \star}, t=7.660, d f=6, p=0.000259$ compared to control. c Normalized 5 hmC tag density distribution from Tet1 cKO and control OPCs. TSS transcription start site, TTS transcription terminal site. $\mathbf{d}$ Heatmap of $5 \mathrm{hmC}$ signal from $\pm 5 \mathrm{~kb}$ of TSS at all annotated genes in control and Tet1 CKO OPCs. e Quadrant plot of differentially hydroxymethylated peaks at gene bodies and differentially expressed genes (Tet1 cKO vs. Control, $p<0.05$ ). The $x$-axis is $\log _{2}$ fold change of transcript level, and the $y$ axis is the difference in DNA

hydroxymethylation. Dashed lines indicate a twofold difference. Genes indicated are involved in OL differentiation, cell division, and calcium transporter. $\mathbf{f}$ Gene ontology (GO) analysis for downregulated and hypo-hydroxymethylated gene groups in Tet7- ablated OPCs. $\mathbf{g}$, $\mathbf{h}$ 5hmC enriched genes involved in myelination ( $\mathbf{g}$ ) and calcium transport (h) from control (blue) and Tet1 cKO (orange) OPCs. Tracks were visualized with Mochiview v1.46. i GSEA plots of genes involved in calcium ion transmembrane transporter activity in control and Tet1-mutant OPCs. $\mathbf{j}$ Quantitative real-time PCR of genes involved in calcium ion transmembrane transporter activity in control and Tet1 CKO OPCs. Data were Means \pm SEM of transcript levels relative to control after normalization from $n=3$ independent experiments each performed in triplicate. Two-tailed unpaired $t$-test. Itpr2: ${ }^{\star}, t=12.124, d f=4, p=0.006 ;$ Cacna1a: ${ }^{\star *}, t=8.606, d f=4, p=0.001002 ;$ Cacna1c: ${ }^{\star *}, t=13.36, d f=4, p=0.0002 ;$ Cacna2d1: ${ }^{\star \star \star}, t=17.90, d f=4, p<0.0001 ;$ Cacnb4: ${ }^{\star \star \star}, t=27.209, d f=4$, $p=0.000011 ;$ Cacng5: ${ }^{\star \star \star}, t=32.76, d f=4, p<0.0001 ;$ Atp2b1: ${ }^{\star \star \star}, t=11.47, d f=4, p=0.0003 ;$ Atp2c1: ${ }^{\star \star \star}, t=18.896, d f=4, p=0.000046 ;$ Slc8a1: ${ }^{\star \star \star}$, $t=12.47, d f=4, p=0.0002$

ATP-induced calcium rise (Fig. 9b, c). Similar to the above rescue assay with Bay K 8644 application, we revealed by immunostaining that the addition of Ada significantly increased the differentiation ability of Tet 1 cKO OPCs in culture (Supplementary Fig. 12d-f).

Given that TET1 regulates a set of genes in the calcium transport, activation of a single gene Itpr2 might not be able to fully rescue the calcium defects in Tet1 cKO mice. We then examined the in vivo function of ITPR2 on OL differentiation by generating Itpr2 conditional knockout mice Itpr2 cKO (Itpr2 $2^{\text {flox/flox; Olig1-Cre }}{ }^{+l-}$ ). To assess Cre-mediated Itpr2 depletion, we quantified ITPR2 expression in OLIG2 ${ }^{+}$cells from Itpr $2 \mathrm{cKO}$ and control mice at P14. Immunostaining revealed that expression of ITPR2 in the corpus callosum was significantly lower in Itpr2 cKO than in control mice (Fig. 9h, i). Quantitative real-time PCR further confirmed the specific ablation of Itpr2 in purified OPCs, but not in astrocytes (Supplementary Fig. 12g). Examination of the expression of stage-specific OL lineage markers revealed that the percentage of $\mathrm{CC}^{+}$mature OLs was significantly reduced in Itpr $2 \mathrm{cKO}$ cortices compared to controls at P7 and P14 (Fig. 9j, 1), whereas the number of PDGFRa ${ }^{+}$OPCs increased (Fig. 9j, k). Myelin protein expression was also substantially decreased in Itpr2 cKO mice at P31 (Fig. 9m). EM of P16 optic nerves revealed that the number of myelinated axons was significantly reduced in Itpr 2 mutants (Fig. 9n, o), and the $G$ ratio was higher in mutants (Fig. 9p). Similar to the phenotypes in adult Tet1 cKO mice, the developmental deficiency of Itpr 2 mutants was recovered in adult animals, as indicated by the comparable number of $\mathrm{CC}^{+}$OLs and $\mathrm{NG}_{2}{ }^{+}$OPCs between control and Itpr2 mutant animals at P60 (Fig. 9k, 1 and Supplementary Fig. 12h). Together, these results suggest that as one of the target genes of TET1-5hmC, ITPR2 accumulates after cell cycle withdrawal and is involved in the initiation of OL differentiation, probably by effectively releasing calcium from ER.

\section{Discussion}

TET1 functions stage-specifically in OL development and remyelination. Methylation of cytosine on CpG islands in the genome enables stable but reversible transcription repression and is critical for mammalian development ${ }^{7,8}$. Defects in the regulation of DNA methylation are associated with various neurological diseases $^{50,51}$. TET enzymes catalyze the first step of DNA demethylation by oxidizing $5 \mathrm{mC}$ into $5 \mathrm{hmC}^{10-12}$. Strikingly, we detected a genome-wide change in the DNA demethylation landscape marked by $5 \mathrm{hmC}$ during OPC differentiation from NPCs, suggesting a role of TET-mediated DNA demethylation in the regulation of OL lineage progression.

We found that TET1, but not TET3, is critical for OPC proliferation, differentiation, and myelination during early animal development, suggesting a unique function of TET1 in oligodendrogenesis and subsequent myelinogenesis. Our observation is different from another study that Tet1 depletion has little effect on OPC-to-OL differentiation in the young mouse brain

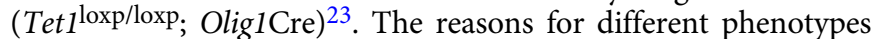
between two mouse lines are not immediately clear. We speculate that the use of different Tet1-floxed strains might contribute to the phenotypic discrepancy during early developmental stages. In our study, the Tet1-mutant mice lack exons 11-13, encoding the catalytic domain of TET1 enzyme ${ }^{24}$, while Tet1-mutant mice lacking exon 4 (Tet1 $\Delta \mathrm{e} 4)^{52}$ were used in the other study ${ }^{23}$. Distinct phenotypes and gene expression changes have been reported among individual Tet 1 -mutant mice lacking exon $4^{52}$ or exon 11-12 24 . Thus, it is possible that the phenotype discrepancy observed in different Tet1-mutant mice might be due to the nature of the mutations disrupting specific Tet1 isoforms, as suggested by the alternative splicing forms of the Tet 1 gene ${ }^{53}$. In addition, other possibilities such as differences in Olig1-Cre lines, mosaicism, and mouse backgrounds used in the studies might also contribute to the phenotypic discrepancy.

Despite early developmental defects, we noticed that the developmental myelin deficiencies recovered in adult Tet $1 \mathrm{cKO}$ mice. TET1 expression is downregulated in OLs from old mice, and we observed weak TET1 expression in a population of OLs $(\sim 29 \%)$ in adult Tet 1 cKO mice, more than $\sim 12 \%$ TET $1+$ OLs in Tet1 mutants at $\mathrm{P} 4$. Thus, myelin deficiencies that recovered in adult Tet $1 \mathrm{cKO}$ mice might be in part due to the escape from Cre-mediated Tet 1 depletion in a population of OL lineage cells. Similar observations have been suggested in other studies, e.g., for the recovered myelin deficiency in adult Dicer1 cKO mice ${ }^{54}$. In addition, it is also possible that the myelination process is not affected in adult OLs lacking TET1 expression, therefore, TET1 may not be essential for myelinogenesis in mature OLs. Furthermore, the remyelination capacity after injury was compromised in adult Tet1 OPC-iKO brains, suggesting that TET1 is also critical for the myelin regeneration process.

Although OL differentiation defects were not due to increased apoptosis in the Tet1-mutant brain, we found that OPC cell cycle progression, especially $\mathrm{G} 2$ to $\mathrm{M}$ phase transition, was impaired in developing Tet $1 \mathrm{cKO}$ animals. In line with this result, we showed that factors involved in cell-cycle regulation, Ccng2, Cdca3, Ccna2, Ccnb1, and Cdc25b55-59, were 5hmC enriched genes in OPCs and were downregulated in Tet1 cKO OPCs. In particular, CCNB1 (Cyclin B1) is the regulatory subunit of CDK1 serine/threonine kinase, and accumulation of CCNB1 is a prerequisite for mitotic initiation in the late G2 
a

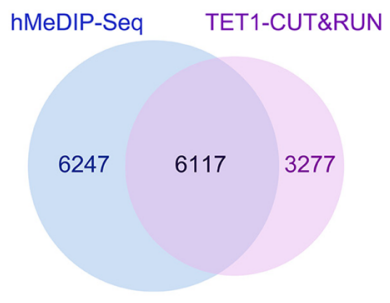

b

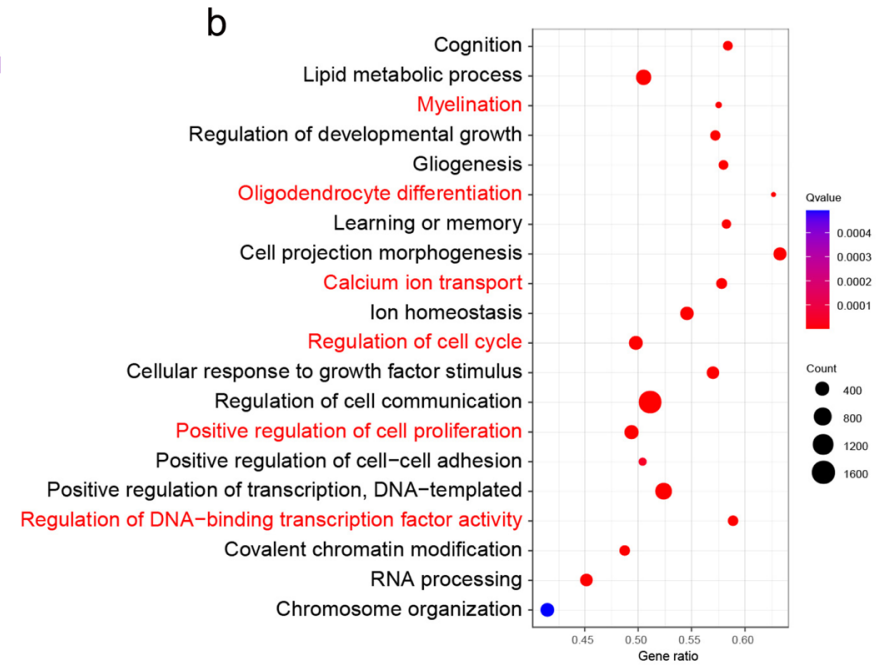

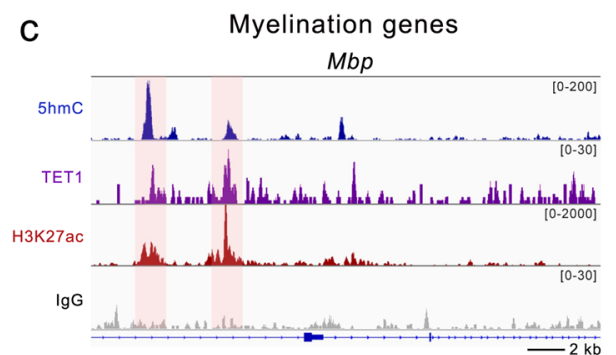

Cldn11
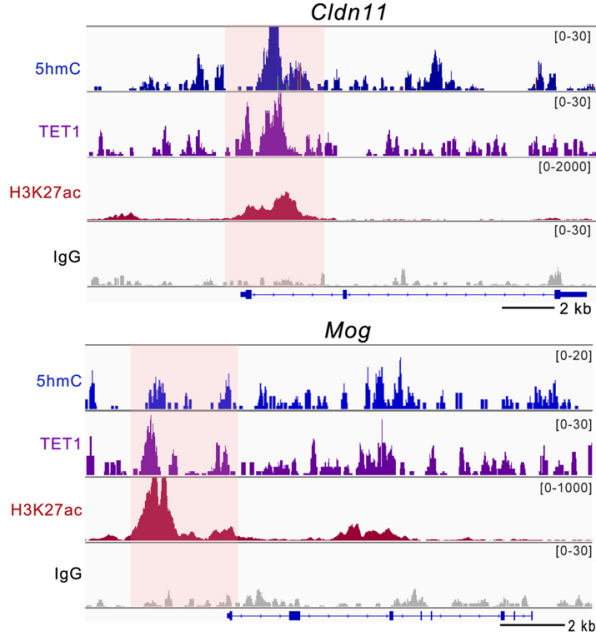

Calcium transport genes

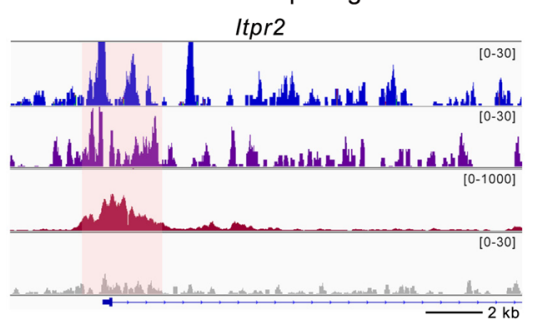

Cacna1a
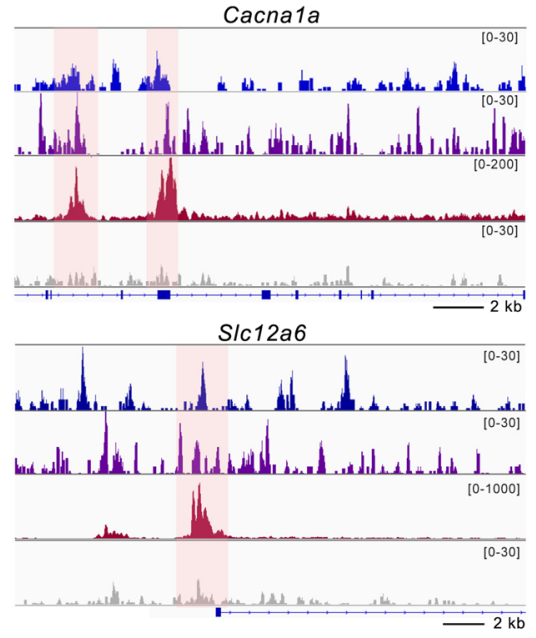
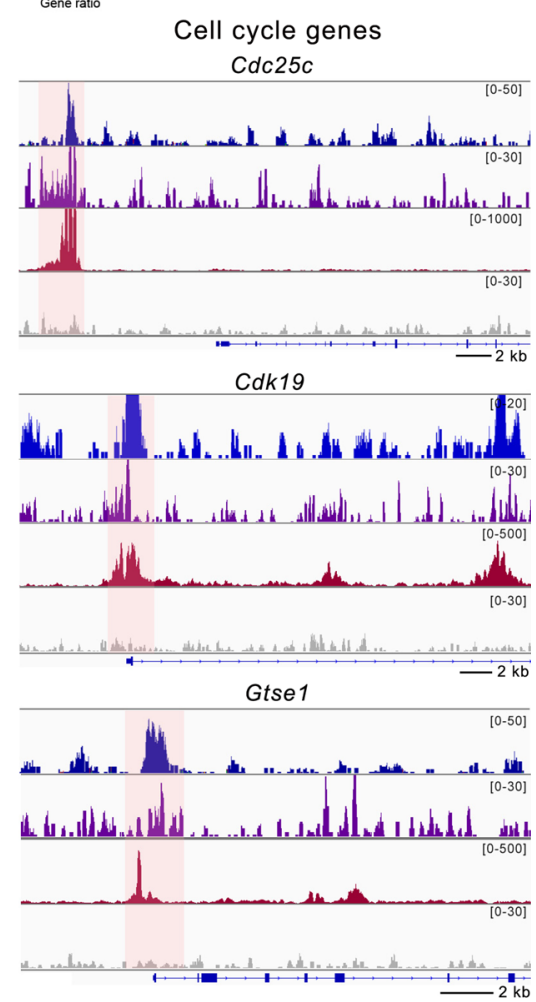

Fig. 8 Cut \& Run-Seq analysis identify TET1 target genes in OPCs. a Venn diagram comparing hydroxymethylated genes and TET1 binding genes in OPCs. b GO analysis for TET1 and 5hmC overlapping target genes in wild-type OPCs. GO terms labeled in red indicate the associated functions of TET1 in our observations. c Snapshots comparing 5hmC profiles, TET1 binding profiles, and H3K27ac profiles in representative genes in OPCs.

phase $^{60}$. Consistently, TET1 has been also implicated in stabilizing CCNB1 in trophoblast stem cells and can act as a facilitator of mitotic cell-cycle progression ${ }^{34,61}$. Therefore, it is possible that TET1 may regulate the expression of cell cycle regulators, CCNB1 stability, or both, in OPCs. Although the precise mechanism for cell cycle transition block in Tet $1 \mathrm{cKO}$ OPCs remains unknown, our observations suggest an important role of TET1 in OPC cell-cycle progression.

TET1-5hmC functions in psychological disorders. In recent years, TET-5hmC association with psychiatric and cognitive disorders has gained increasing recognition ${ }^{28-30}$. A cohort of new autosomal recessive genes for intellectual disability, including the missense mutations in TET1, has been identified ${ }^{62}$. A previous report using the same Tet $1^{\text {loxp }}$ line indicated that Tet $1 \mathrm{KO}$ mice exhibited delayed spatial learning and deficient short-term memory retention in $\mathrm{MWM}^{24}$. In contrast, in another study using a different Tet1 KO line ( ${ }^{\Delta}$ Exon 4$)$, no significant differences were observed between groups during the training and the probe trials; but short-term memory extinction was impaired in this Tet $1 \mathrm{KO}$ mice ${ }^{63}$.

TET1 together with other factors such as ERBB4, BDNF was identified as independent predictors of schizophrenia and serves as a high-risk gene for schizophrenia ${ }^{31}$. Loss of normal PPI of startle, in particular, is widely accepted as an endophenotype of schizophrenia and considered indicative of disrupted sensorimotor gating, a precognitive process to prevent sensory overload and cognitive fragmentation ${ }^{32,64,65}$. Besides, the prodromal cognitive symptoms of schizophrenia often precede the occurrence of psychosis, and the range of cognitive deficits in schizophrenia suggests an overarching alteration in cognitive control, the ability 

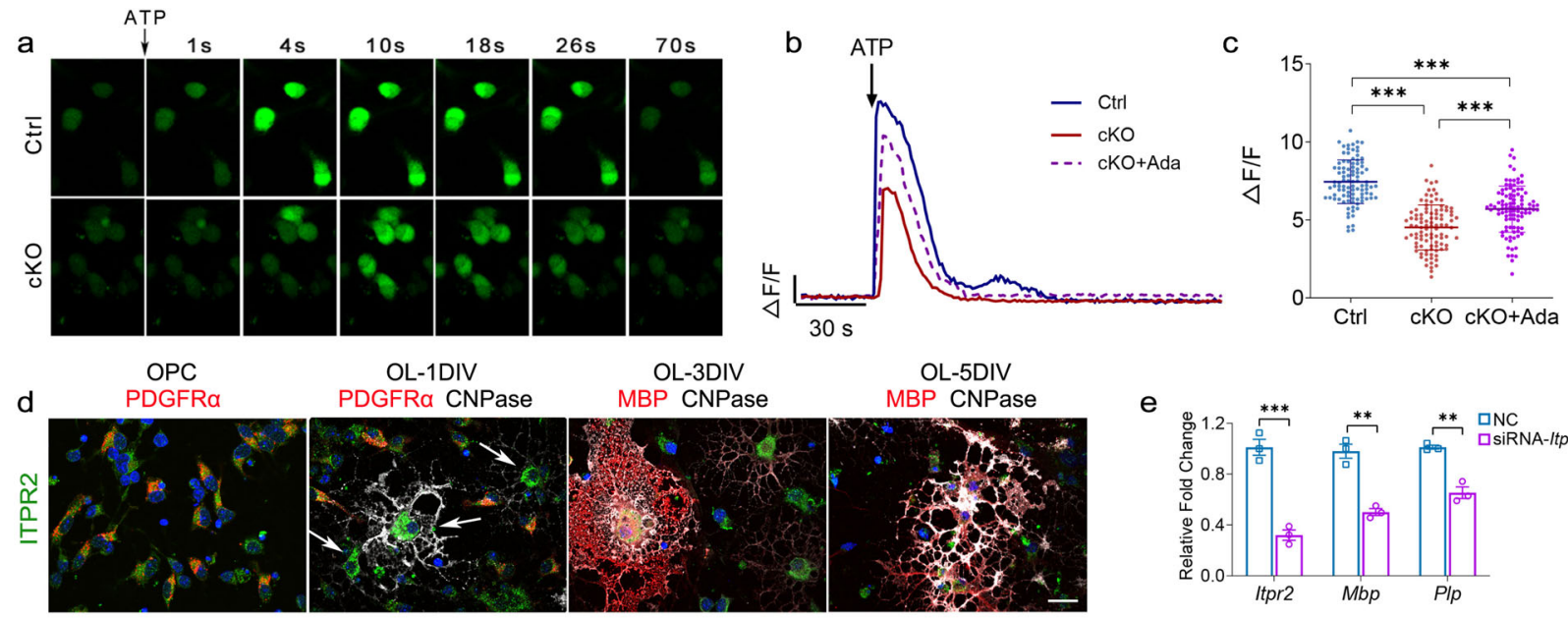

e
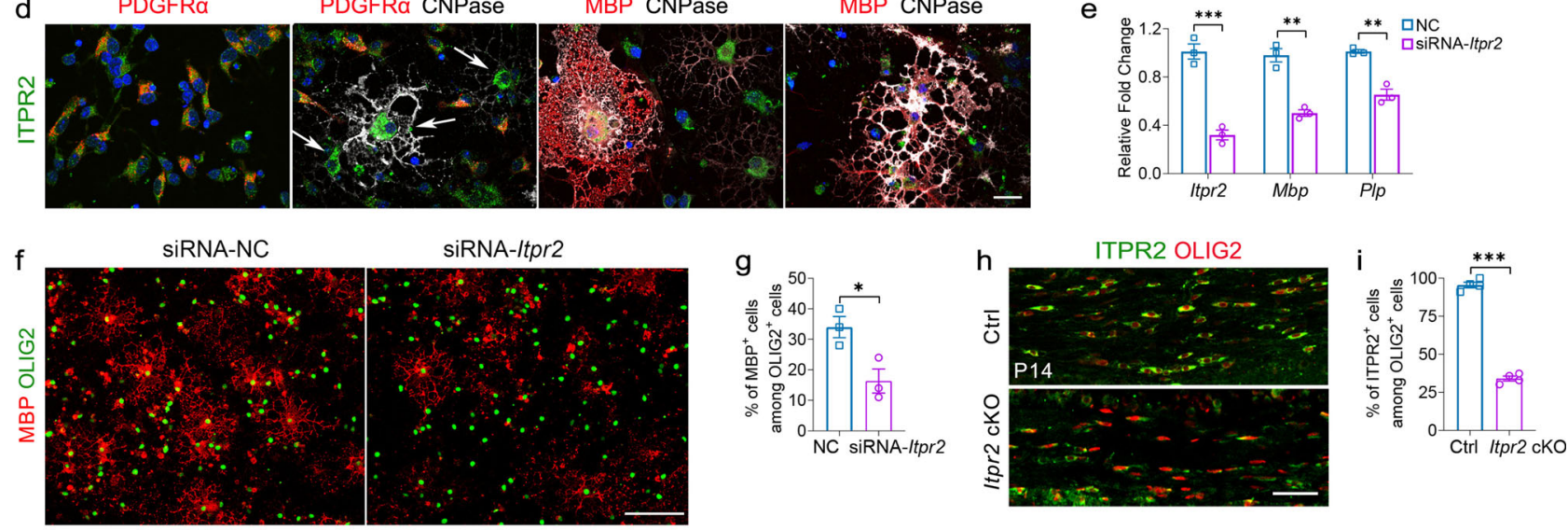
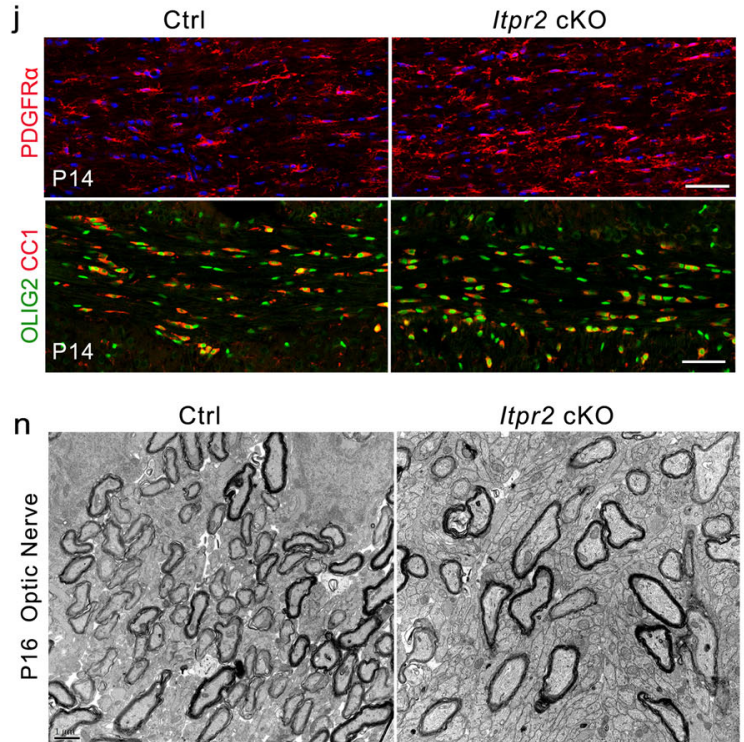
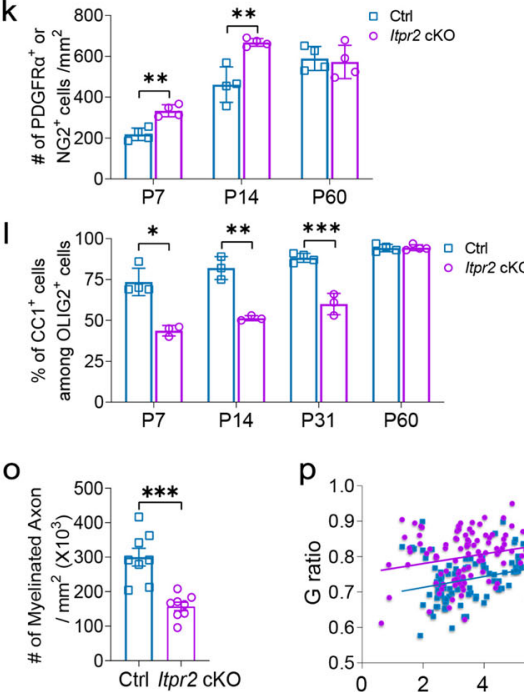
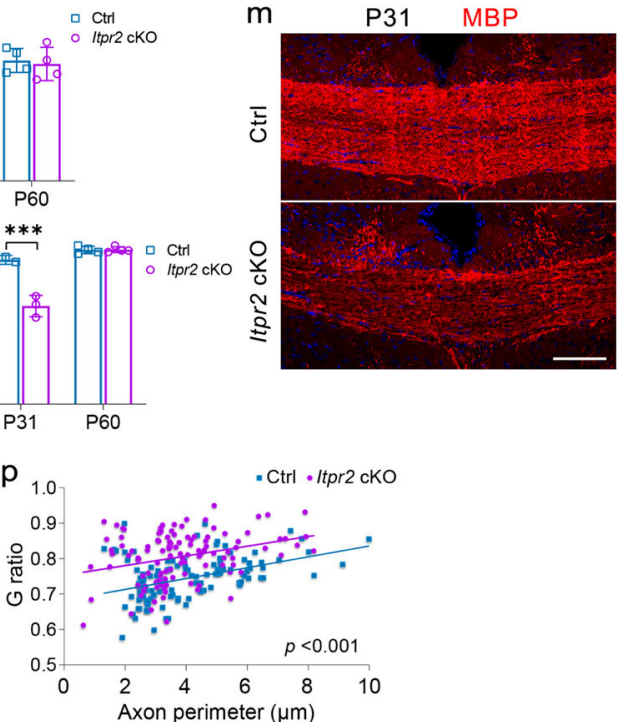

to adjust thoughts or behaviors in order to achieve goals ${ }^{66-68}$. We find that mice with Tet 1 loss in the OL lineage exhibit impaired PPI and working memory deficits, two of the core symptoms related to schizophrenia. Thus, our studies demonstrate a crucial function of TET1-mediated epigenetic modifications in OLs for psychological disorders.

Locus-specific alterations of DNA hydroxymethylation in OPCs of Tet1 mutants. Levels of $5 \mathrm{hmC}$ are variable in the promoter and gene body regions ${ }^{69}$ and impact gene expression in a cell type-dependent manner ${ }^{18,70,71}$. Our comparison of differentially hydroxymethylated genes with transcriptome profiles indicated that $5 \mathrm{hmC}$ signals in gene bodies are more significantly associated with gene expression changes than those in promoter regions in OPCs. This suggests that $5 \mathrm{hmC}$ modification by TET1 regulates locus-specific gene expression programs necessary for OPC differentiation. Although the exact mechanism of gene body $5 \mathrm{hmC}$ in regulating gene expression is unclear, there are many observations indicating the association between enriched $5 \mathrm{hmC}$ in the gene body and the active transcription in different tissues ${ }^{36,72-75}$. One possibility is that $5 \mathrm{mC}$ oxidation relieves a repressive effect on transcription, perhaps by counteracting spurious intragenic antisense transcription ${ }^{76}$. Other explanations may include the fact that $5 \mathrm{hmC}$ has a destabilizing effect on DNA structure that potentially favors the opening of the double helix by the transcription apparatus ${ }^{77,78}$. Moreover, $5 \mathrm{hmC}$ enriched in the gene body cannot be bound by transcriptionally repressive methyl-CpG binding domain (MBD) proteins in vitro ${ }^{79,80}$. These studies suggested that gene body $5 \mathrm{hmC}$ levels may regulate the transcription rate by modifying the accessibility of genic chromatin to transcriptional machinery or by inhibiting the binding of repressive methyl-CpG binding proteins (MBDs). How $5 \mathrm{hmCs}$ cooperate with other epigenetic regulators for OPC differentiation remains to be determined. 


\section{Fig. 9 Impaired calcium transport in Tet1 cKO OPCs and depletion of ITPR2, a TET1-5hmC target gene, inhibits developmental myelination.}

a Representative serial image was obtained after the addition of $100 \mu \mathrm{M}$ ATP to OPCs from control or Tet1 cKO mice. b Representative traces of Fluo4 intensity in OPCs from control and Tet1 cKO mice following application of ATP. Agonist for ITPR2, Ada, is added to rescue impaired calcium rise in Tet1 cKO mice. c Amplitude changes $(\Delta F / F)$ after ATP treatment of control and Tet1 cKO OPCs. ITPR2 agonist Ada is used to rescue calcium rise deficiency in Tet1 cKO mice. Data were Means \pm SD ( $n=97$ cells in Ctrl group from three independent cultures, $n=99$ cells in cKO group from three independent cultures, $n=100$ cells in cKO + Ada group from three independent cultures). One-way ANOVA, $F_{(2,293)}=102.001, p<0.000001$. Tukey's multiple comparisons test: Ctrl vs. $\mathrm{cKO}:{ }^{\star \star \star}, q=2.9233, p<0.0000001, \mathrm{Ctrl}$ vs. $\mathrm{cKO}+$ Ada: ${ }^{\star \star \star}, q=1.75171, p<0.0000001, \mathrm{cKO}$ vs. $\mathrm{cKO}+$ Ada: ${ }^{\star \star \star}, q=-1.17160$,

$p<0.0000001$. $\mathbf{d}$ Representative images of ITPR2 immunostaining during OPC differentiation in vitro. Arrows indicate the highest level of ITPR2 in newly formed CNPase ${ }^{+}$oligodendrocytes from 1DIV differentiation cultures, which does not appear in other stages. Scale bar, $10 \mu \mathrm{m}$. e Quantitative real-time PCR identified the efficiency of a siRNA-Itpr2 duplex in reducing the mRNA level of Itpr2 in normal OPCs and in repressing the expression of two myelin genes, Mbp and Plp, in differentiating OLs, respectively. Transfection with nontargeting duplex was used as negative control (NC). Data were Means \pm SEM ( $n=3$ transfections). Two-tailed unpaired $t$-test. Itpr2: ${ }^{\star \star \star}, t=9.174, d f=4, p=0.000784 ; M b p:{ }^{\star \star}, t=8.083, d f=4, p=0.001273 ; P l p:{ }^{\star \star}, t=7.528$, $d f=4, p=0.001667$. f Immunostaining for MBP and OLIG2 in OL cultures after transfected with siRNA-Itpr2 duplex for 4 days. Scale bar, $100 \mu$ m. $\mathbf{g}$ Quantification of the percentage of $\mathrm{MBP}^{+}$cells among $\mathrm{OLIG}^{+}$cells after siRNA transfection. Note the significant decrease of differentiated cells in the siRNA-Itpr2 transfected group. Data were Means \pm SEM ( $n=3$ transfections). Two-tailed unpaired $t$-test, ${ }^{\star}, t=3.372, d f=4, p=0.028$ compared to control. h Representative double immunostaining for ITPR2 and OLIG2 in P14 corpus callosum from control and Itpr2 cKO mice. Scale bar, $50 \mu \mathrm{m}$. i Percentage of ITPR2 ${ }^{+}$cells among OLIG2 $2^{+}$OLs in P14 corpus callosum of control and Itpr 2 cKO mice. Data were Means \pm SEM $(n=4$ animals in each group). Two-tailed unpaired $t$-test, ${ }^{\star \star \star}, t=25.304, d f=6, p<0.00001$ compared to control. $\mathbf{j}$ Immunostaining for OPC marker PDGFR $\alpha$ and double immunostaining for OL lineage marker OLIG2 and mature OL marker CC1 in corpus callosum from P14 Itpr2 cKO mice. Scale bar, $50 \mu \mathrm{m}$. $\mathbf{k}$ Quantification of the density of PDGFR $\alpha^{+}$cells in P7 and P14 mice revealed a significant reduction in Itpr2 cKO mice. No difference in density of NG2+ cells was observed in P60 adult mice. Data were Means $\pm \operatorname{SEM}\left(n=4\right.$ animals per group). Two-tailed unpaired $t$-test, $\mathrm{P} 7:{ }^{\star \star}, t=-5.411, d f=6, p=0.002 ; \mathrm{P} 14:{ }^{\star}, t=-4.668$, $d f=6, p=0.003 ; \mathrm{P} 60: t=0.336, d f=6, p=0.748$ compared to control. I Quantification the percentage of CC1+ cells among OLIG2+ cells from P7 to P31 mice revealed significant reduction in Itpr2 cKO mice. No difference was observed at P60 adult mice. Data were Means \pm SEM $(n=4$ animals in control group and three animals in mutant). P7: ${ }^{\star}$, Mann-Whitney $U$-test, $z=-2.141, p=0.032$. Two-tailed unpaired $t$-test, $\mathrm{P} 14:{ }^{\star \star}, t=7.414, d f=4, p=0.002$; P31: ${ }^{\star \star \star}, t=7.931, d f=5, p=0.0005 ; \mathrm{P} 60: t=0.178, d f=6, p=0.865$ compared to control. $\mathbf{m}$ Representative images for MBP staining in corpus callosum from P31 Itpr2 cKO mice. Scale bar, $50 \mu \mathrm{m}$. $\mathbf{n}$ Representative electron micrographs of P16 optic nerves from control and Itpr2 cKO mice. Scale bar, $1 \mu \mathrm{m}$. - Quantification of the number of myelinated axons in defined areas from optic nerves of control and Itpr2 cKO mice. Data were Means \pm SEM ( $n=8$ slides from three animals per group). Two-tailed unpaired $t$-test, ${ }^{\star \star \star}, t=5.035, d f=14, p=0.00018$ compared to control. $\mathbf{p} \mathrm{G}$ ratios vs. axonal perimeters for control and Itpr2 cKO mice reveal a significant difference. Friedman $M$ test, $\chi^{2}=39.035, d f=1, p_{\text {between group }}<0.001$ ( $>110$ myelinating axon counts from three animals each genotype).

Intriguingly, ablation of Tet1 led to the upregulation of a set of genes in OPCs, indicating that TET1 may also function as a transcriptional repressor. Consistent with our data, inhibition of Tet1 expression increased the level of a set of genes in ESCs ${ }^{81,82}$. TET1-mediated repression might involve recruitment of the MBD3/NuRD repressor complex, which was shown to co-localize with TET1 in ESCs ${ }^{83}$. TET1 may also coordinate with the SIN3A co-repressor complex, which shows a similar binding profile to TET1 and is required for a subset of TET1-repressed target genes $^{81,84}$. A recent study indicates that TET1-mediated transcriptional repression could channel through the JMJD8 demethylase transcriptional repressor and is independent of TET1 catalytic activity during epiblast differentiation ${ }^{85}$. The mechanisms of locusspecific transcriptional regulation by TET1 during OL development remain to be further defined.

TET1-5hmC regulates calcium transport to control proper OL differentiation. Calcium signaling is important for OPC migration, differentiation, and initiation of myelin formation ${ }^{86-89}$. For instance, blocking of voltage-gated $\mathrm{Ca}^{2+}$ entry in OPCs inhibits their maturation and myelin formation ability ${ }^{42}$. Similarly, an increase of the resting $\left[\mathrm{Ca}^{2+}\right]_{\mathrm{i}}$ through membrane depolarization facilitates MBP synthesis in OPCs ${ }^{87}$. We found that Tet 1 deletion led to the downregulation of multiple calcium transporter genes in OPCs, which mediated the impaired intracellular store release and extracellular influx in response to a stimulus. Moreover, treatment with a calcium channel agonist reversed the differentiation defects in Tet1-deficient OPCs, thus indicating the significance of TET1-5hmC regulated calcium transport in OLs.

We find that ITPR2, an intracellular ER calcium channel that is exclusively expressed in postmitotic $\mathrm{OLs}^{43,44}$, is one of the TET1-5hmC targets. Expression of ITPR2 is upregulated during a motor learning task ${ }^{44}$, indicating the participation of ITPR2 ${ }^{+}$
OLs in myelin plasticity. We find that deletion of Itpr2 in the OL lineage greatly reduces OPC differentiation, suggesting that ITPR2 is critical for the initiation of myelination. In addition to ITPR2, we have also detected solute carrier (Slc) gene family members as TET1-5hmC targets. Among these genes, Slc12a2 is reported responsible for defective myelin regeneration detected in old Tet 1 cKO mice ${ }^{23}$. Therefore, TET1-mediated genomewide DNA hydroxymethylation may regulate multiple distinct targets including Itpr2 and Slc12a2 for optimal myelinogenesis or at different stages of OL lineage cells.

Together, TET1-mediated 5hmC modification, or DNA hydroxymethylation, can modulate the process of oligogenesis and myelinogenesis through at least two critical processes, by fine-tuning cell cycle progression for OPC proliferation and by regulating OL homeostasis e.g., ITPR2-mediated calcium transport, for OL myelination.

\section{Methods}

Animals, immunohistochemistry, and EM. All animal experiment protocols were approved by the Animal Care and Use Committee of the Fourth Military Medical University and were conducted in accordance with the guidelines for the care and use of laboratory animals. All mice used in this study were kept under stable 12-h circles of darkness and light in the respective facilities. Room temperature was kept between $20-24{ }^{\circ} \mathrm{C}$ and air humidity between $45-65 \%$ as documented in daily controls. Tet 1 flox/flox mice $^{24}$ and Tet 3 flox/flox mice ${ }^{18}$ were crossed with heterozygous Olig1-Cre mice ${ }^{25,90}$ to generate Tet $1{ }^{\text {flox } /{ }^{+}} ;$Olig1Cre ${ }^{+/-}$mice and Tet $3{ }^{\text {flox } /{ }^{+}} ;$Olig1Cre ${ }^{+/-}$mice, which were then bred with Tet 1 flox/flox or Tet 3 flox/flox mice to produce Tet $1 \mathrm{cKO}$ (Tet 1 flox/flox;Olig1Cre ${ }^{+/-}$) or Tet3 cKO (Tet3 flox/flox;Olig1Cre ${ }^{+/-}$) offspring, respectively. NG2CreER mice ${ }^{35}$, R26-EYFP mice (Stock No: 006148), and R26tdTomato mice (Ai14) (Stock No: 007914) were from Jackson lab. Itpr2 flox/flox line $^{91}$ was provided by the RIKEN BRC (RBRC10293) through the National Bio-Resource Project of the MEXT/AMED, Japan. It was crossed with heterozygous Olig1-Cre mice to generated Itpr2 cKO (Itpr2 flox/flox;Olig1Cre ${ }^{+/-}$) as stated above. For tamoxifen treatment of Tet1 flox/flox; NG2CreER mice, tamoxifen (Sigma, T5648) was dissolved in corn oil (Sigma, C8267) and injected intraperitoneally at $3 \mathrm{mg} / 40 \mathrm{~g}$ (body weight) per day. 
For immunohistochemistry, cryosections $(14 \mu \mathrm{m})$ of brains were short-fixed $30 \mathrm{~min}$ in $4 \%$ paraformaldehyde and processed for antigen retrieval. Sections were treated with $10 \mathrm{mM}$ sodium citrate ( $\mathrm{pH} 6.0$ ) at $\sim 90^{\circ} \mathrm{C}$ for $10 \mathrm{~min}$ in a microwave and cooled down in room temperature. Then sections were washed three times in PBS, blocked in 3\% BSA with 0.03\% Triton X-100 (blocking buffer) for $1 \mathrm{~h}$ at RT, and incubated with primary antibodies in blocking buffer overnight at RT. The next day, sections were washed three times in PBS, incubated with secondary antibodies at RT for $2 \mathrm{~h}$, and then counterstained with DAPI for $5 \mathrm{~min}$. Finally, sections were washed three times in PBS and mounted. Images were taken on an Olympus FV1200 Confocal microscope. We used antibodies against OLIG2 (Millipore AB9610, 1:500), SOX10 (Santa Cruz 17342, 1:50), TET1 (Genetex 124207, 1:100), PDGFRa (Abcam ab61219, 1:500), CC1 (Oncogene Research OP80, 1:200), MBP (Abcam ab7349, 1:500), 5hmC (Active motif 39769, 1:1000), NeuN (Millipore ABN78, 1:800), PV (Abcam ab11427, 1:200), SST (Millipore AB5494, 1:50), VIP (CST 63269, 1:200), ALDH1L1 (Proteintech 17390-1-AP, 1:100), CNPase (Sigma C5922, 1:500), Ki67 (Abcam ab16667, 1:500), GFAP (Millipore mAB360, 1:1000), GST-pi (Abcam ab53943, 1:50), NESTIN (Genetex GTX630201, 1:500), DCX (Millipore ab2253, 1:500), ITPR2 (Millipore ab3000, 1:50), and H3S10P (Cell Signaling Technology 9706, 1:500).

For BrdU pulse labeling in P1 pups, animals were injected intraperitoneally with $100 \mathrm{mg} \mathrm{BrdU} / \mathrm{kg}$ body weight $2 \mathrm{~h}$ prior to sacrifice. For the staining of BrdU, as well as $5 \mathrm{hmC}$, before permeabilization, sections were subjected to DNA denaturation with $2 \mathrm{M}$ hydrochloric acid at $37^{\circ} \mathrm{C}$ for $20 \mathrm{~min}$ and then neutralized with $0.1 \mathrm{M}$ sodium borate at $\mathrm{pH} 8.5$ for $2 \times 10 \mathrm{~min}$. The G3G4 monoclonal antibody (antiBrdUrd, 1:40) was obtained from the Developmental Studies Hybridoma Bank developed under the auspices of the NICHD and maintained by The University of Iowa.

For TUNEL/OLIG2 double staining, OLIG2 immunostaining were applied after the DeadEnd ${ }^{\mathrm{m}}$ Fluorometric TUNEL System kit (Promega, G2350) to reveal TUNEL positive cells in OL lineage.

For EM, tissues were dissected and fixed in $2 \%$ glutaraldehyde $+4 \%$ paraformaldehyde in $0.1 \mathrm{M}$ cacodylate buffer $(\mathrm{pH} 7.2)$ at $4{ }^{\circ} \mathrm{C}$ for $24 \mathrm{~h}$. The brain was coronally sliced at the $50-\mu \mathrm{m}$ thickness and treated with $2 \%$ osmium tetroxide overnight before being subjected to a standard protocol for epoxy resin embedding. Tissues were sectioned at $1 \mu \mathrm{m}$ and stained with toluidine blue. Ultrathin sections were cut onto copper grids and stained with uranyl acetate before being examined with a JEM-1230 electron microscope (JEOL LTD, Tokyo, Japan), which is equipped with a CCD camera and its application software (832 SC1000, Gatan, Warrendale, PA).

Western blot assay. For Western blot assay, whole-cell lysates were prepared from tissue or cultures using RIPA buffer ( $150 \mathrm{mM} \mathrm{NaCl}, 50 \mathrm{mM}$ Tris- $\mathrm{HCl}$ (pH 7.4), $1 \%$ NP40, $1 \mathrm{mM}$ PMSF, $1 \times$ Roche complete mini protease inhibitor cocktail, and $1 \times$ Pierce phosphatase-inhibitor cocktail). Protein concentrations in centrifugationclarified cell lysates were measured by the BCA Protein Assay Kit (Pierce) and equal amounts of protein $(10 \mu \mathrm{g})$ were separated on SDS-PAGE gel and transferred to Hybond PVDF (Amersham Biosciences). For protein blotting, we used antibodies against OLIG2 (Millipore MABN50, 1:1000), MBP (Abcam ab7349, 1:1500), NeuN (Millipore ABN78, 1:2000), ALDH1L1 (Proteintech 17390-1-AP, 1:1000), DCX (Proteintech 13925-1-AP, 1:1000), CCNB1 (Boster BA0766-2, 1:500), $\beta$-actin (Proteintech 66009-1,1:5000), GAPDH (Proteintech, 60004-1, 1:15000), and Tubulin (Abbkine A01030, 1:1000). Signals were developed with horseradish peroxidaseconjugated secondary antibodies (Abbkine), followed by an ECL kit (Zeta LIFE). The band intensity was calculated with Tanon5200 imager and quantified with ImageJ $1.52 \mathrm{p}$ software. The intensity was normalized to $\beta$-actin or Tubulin level expressed as relative fold change against control.

RNA extraction and qRT-PCR. Total RNAs were purified from tissues or cell cultures using TRIzol reagent according to the manufacturer's instruction (Invitrogen). For qRT-PCR, RNA was transcribed to cDNA with the PrimeScript ${ }^{\text {t" }}$ RT reagent Kit (Perfect Real Time, Takara) and reactions were performed with SYBR ${ }^{\circ}$ Premix Ex Taq"' (Takara) in CFX96 Touch Real-Time PCR Detection System (BioRad). Relative gene expression was calculated by Bio-Rad CFX Manager and normalized to internal control $\beta$-actin. Primer sequences for SybrGreen probes of target genes are listed in Supplementary Table 3.

Culture of OPCs and immunocytochemistry. Rodent OPCs were isolated from P6 cortices of animals by immunopanning with antibodies against RAN-2, GalC, and $\mathrm{O} 4$ sequentially ${ }^{92}$. Briefly, cerebral hemispheres were diced and digested with papain at $37^{\circ} \mathrm{C}$. Following gentle trituration, cells were resuspended in a panning buffer containing insulin $(5 \mu \mathrm{g} / \mathrm{ml})$ and then incubated at room temperature sequentially on three immunopanning dishes: RAN-2 (ATCC \#TIB-119, 1:5 hybridoma supernatant), anti-GalC (1:5 hybridoma supernatant) ${ }^{93}$, and O4 (1:5 hybridoma supernatant $)^{94} . \mathrm{O}^{+} \mathrm{GalC}^{-}$OPCs were released from the final panning dish with trypsin (Sigma). To induce the differentiation of OPCs, mitogens in the culture medium (FGF and PDGFaa) were replaced with T3, NAC, and CNTF.

For immunocytochemistry, cell cultures were fixed in 4\% PFA. After Triton X-100 permeabilization for $15 \mathrm{~min}$, samples were incubated with primary antibody for $1 \mathrm{~h}$ at room temperature followed by the fluorescent secondary antibody for another hour. Cells were then counterstained with DAPI and visualized with a confocal microscope. Experiments were replicated using cells from three different primary cultures.

Flow cytometric analysis of cell cycle with propidium iodide DNA staining. PI staining for flow cytometry was performed according to the user manual of DNA Content Quantitation Assay (Cell Cycle) from Solarbio (\#CA1510). Briefly, OPCs from control or Tet1 cKO mice were harvested, washed in PBS, and fixed in cold $70 \%$ ethanol for $30 \mathrm{~min}$ at $4{ }^{\circ} \mathrm{C}$. After washing twice in PBS, cells were treated with RNase and then stained with PI. With guava easyCyte6HT (Millipore), the forward scatter (FS) and side scatter (SS) were measured to identify single cells. For analysis, ModFit LT 5.0 software was used to make the PI histogram plot. Experiments were replicated three times.

Lysolecithin-induced demyelinating injury. Lysolecithin-induced demyelination was carried out in the corpus callosum of 8-week-old mice. Anesthesia was induced and maintained by peritoneal injection of a mixture of ketamine $(90 \mathrm{mg} / \mathrm{kg})$ and xylazine $(10 \mathrm{mg} / \mathrm{kg})$. The skull was exposed, and a hole was cut into the cranium. Focal demyelinating lesions were induced by stereotaxic injection of $0.8 \mu \mathrm{l} 1 \%$ lysolecithin solution (L-a-lysophosphatidylcholine, Sigma L4129) into the corpus callosum at coordinates: $0.8 \mathrm{~mm}$ lateral, $0.8 \mathrm{~mm}$ rostral to bregma, $1.2 \mathrm{~mm}$ deep to brain surface) using a glass capillary connected to a $10 \mu \mathrm{l}$ Hamilton syringe. Animals were left to recover in a warm chamber before being returned to their housing cages. LPC-induced injuries were conducted in a genotype-blinded manner.

Electrophysiology. Analyzing the CAP was performed according to previous protocols ${ }^{27,95}$. Tet1 $\mathrm{cKO}$ and control littermates were killed by cervical dislocation and then decapitated. Optic nerves were dissected free and cut between the orbit and the optic chiasm in the standard aCSF containing (in $\mathrm{mM}$ ): $\mathrm{NaCl} 126, \mathrm{KCl} 3.0$, $\mathrm{CaCl}_{2} 2.0, \mathrm{MgCl}_{2} 2.0, \mathrm{NaH}_{2} \mathrm{PO} 41.2, \mathrm{NaHCO}_{3} 26$, and glucose 10 at $37^{\circ} \mathrm{C}$. Following dissection, optic nerves were equilibrated in aCSF for at least $30 \mathrm{~min}$ with constant aeration $\left(95 \% \mathrm{O}_{2} / 5 \% \mathrm{CO}_{2}\right)$. Then the nerve was gently placed in a customized perfusion chamber, maintained at $37^{\circ} \mathrm{C}$, and perfused with aCSF at $2-3 \mathrm{ml} / \mathrm{min}$ speed. Suction electrodes backfilled with aCSF were used for stimulation and recording. One electrode was attached to the rostral end of the nerve for stimulation and the second suction electrode was attached to the caudal end of the nerve to record the CAP, thus all recordings were orthodromic. Stimulus pulse strength (100- $\mu$ s duration, SS-201J Isolator constant current output with SEN-7203 stimulator, Nihon Kohden, Japan) was adjusted to evoke the maximum CAP possible and then increased another $25 \%$ (i.e., supramaximal stimulation). During an experiment, the supramaximal CAP was elicited every $10 \mathrm{~s}$ and repeat ten times. The signal was amplified $100 \times \mathrm{AC}$ membrane potential $(100 \mathrm{mV} / \mathrm{mV})$ by a Multiclamp700B amplifier, filtered at $10 \mathrm{kHz}$, and acquired at $10 \mathrm{kHz}$ by Clampex 10.6 software (Axon Instrument, Molecular Devices, USA). The average CAP amplitude and area were measured in Clampfit 10.6 software (Molecular Devices, USA) offline and performed blind to genotype. Image drawing and statistical analysis were performed in GraphPad Prism 8.

\section{Behavior test}

Startle response/PPI tests. A startle reflex measurement system (Labmaze ZS-ZJT, Beijing) was used to test the startle response and PPI for P42 mice. XeyeStartle software was used to record and analysis the data. Throughout the session, the startle system delivered a constant background white noise of $68 \mathrm{~dB}$. The startle response was recorded for $300 \mathrm{~ms}$ (measuring the response every $1 \mathrm{~ms}$ ) with the onset of the stimulus and a startle response was defined as the peak response during the $300 \mathrm{~ms}$ period.

The acoustic startle begins by placing a mouse in the undisturbed chamber for $5 \mathrm{~min}$. The test consists of ten 20 - $\mathrm{ms}$ bursts of white noise varied in level from $65-125 \mathrm{~dB}$ sound stimuli in steps of $5 \mathrm{~dB}$, plus ten no-stimulus trials. The order of these stimuli was randomized, and the duration of intertrial intervals was $15 \mathrm{~s}$. The PPI test session began with a 5 -min acclimation period followed by three consecutive blocks of test trials. Block 1 and 3 consisted of six startle stimulus-alone trials. Block 2 contained ten startle stimulus-alone trials, ten prepulse + startle trials per prepulse intensity, and ten no-stimulus trials. Three combinations of prepulse and startle stimuli $(70-120,76-120$, and $82-120 \mathrm{~dB})$ were employed. Trials were presented in a pseudorandom order, ensuring that each trial was presented ten times and that no two consecutive trials were identical. Intertrial intervals ranged from 30 to $45 \mathrm{~s}$. Basal startle amplitude was determined as the mean amplitude of the ten startle stimulus-alone trials. PPI was calculated according to the formula: $100 *[1-(\mathrm{PPx} / \mathrm{P} 120)] \%$, in which PPx means the ten PPI trials (PP70, PP76, or PP82 and P120 was the basal startle amplitude).

Morris water maze. The MWM was conducted as described in ref. ${ }^{33}$ with minor modifications. A white plastic tank $120 \mathrm{~cm}$ in diameter was kept in a fixed position and filled with $22^{\circ} \mathrm{C}$ water, which was made opaque with milk. A $10 \mathrm{~cm}$ platform was submerged $1 \mathrm{~cm}$ below the surface of opaque water and located in the center of one of the four virtually divided quadrants. All animal activities were automatically recorded and measured by Smart 3.0 software. P90 mice were tested for MWM. 
The swim training consisted of 5 days of trials, during each day mice were released from four random locations around the edge of the tank with an intertrial interval of about $30 \mathrm{~min}$ and they were allowed to freely swim for a maximum of $60 \mathrm{~s}$ or guided to the platform. Afterward, mice were allowed to stay on the platform for $15 \mathrm{~s}$. A probe trial was performed $24 \mathrm{~h}$ after the last day of training. During the probe trial, mice were allowed to swim in the pool without the escape platform for $60 \mathrm{~s}$. The performance was expressed as the percentage of time spent in each quadrant of the MWM and swim distance in the target quadrant, which were automatically recorded. Moreover, the latency to reach the platform position (using $10 \mathrm{~cm}$ diameter) and the number of crossings through the position were manually recorded.

RNA-seq and data analysis. RNA-seq were performed by RiboBio Co., Ltd. (Guangzhou, China). Briefly, libraries were prepared using Illumina RNA-Seq Preparation Kit (TruSeq RNA Sample Prep Kit) and sequenced by HiSeq 3000 sequencer. RNA-seq reads were mapped to mm10 using TopHat 2.1.1 with settings of "read mismatches=2" and "read gap length=2" (http://ccb.jhu.edu/ software/tophat/index.shtml). TopHat output data were then analyzed by DEGseq (1.39.0) package to compare the changes of gene expression between Tet $1 \mathrm{cKO}$ and control, based on the calculated RPKM values for known transcripts in mouse genome reference. Heatmap of gene differential expression was generated using $\mathrm{R}$ Package (http://www.r-project.org). GO analysis was performed using ToppGene Suite (http://toppgene.cchmc.org) and GSEA 4.0.1 (http://www.broadinstitute.org/ gsea/index.jsp).

hMeDIP-sequencing analysis. hMeDIP-sequencing service was provided by KangChen Biotech (Shanghai, China). hMeDIP-sequencing library preparation was performed according to a previous study ${ }^{96}$ with minor modifications. Genomic DNA was sonicated to $\sim 200-800$ bp with a Bioruptor sonicator (Diagenode). About $800 \mathrm{ng}$ of sonicated DNA was end-repaired, A-tailed, and ligated to singleend adapters following the standard Illumina genomic DNA protocol (FC-1021002, Illumina). After agarose size-selection to remove unligated adapters, the adapter-ligated DNA was used for IP with a mouse monoclonal anti-5hmC antibody (Diagenode, C15200200). For this, DNA was heat-denatured at $94^{\circ} \mathrm{C}$ for $10 \mathrm{~min}$, rapidly cooled on ice, and immunoprecipitated with $1 \mu$ primary antibody overnight at $4{ }^{\circ} \mathrm{C}$ with rocking agitation in $400 \mu \mathrm{l}$ IP buffer (0.5\% BSA in PBS). A nonspecific IgG control was included to normalized DNA modification enrichment. To recover the immunoprecipitated DNA fragments, $20 \mu \mathrm{l}$ of magnetic beads were added and incubated for an additional $2 \mathrm{~h}$ at $4{ }^{\circ} \mathrm{C}$ with agitation. After IP, a total of five washes were performed with an ice-cold IP buffer. Washed beads were resuspended in TE buffer with $0.25 \%$ SDS and $0.25 \mathrm{mg} / \mathrm{mL}$ proteinase $\mathrm{K}$ for $2 \mathrm{~h}$ at $65^{\circ} \mathrm{C}$ and then allowed to cool down to room temperature. DNA was then purified using Qiagen MinElute columns and eluted in $16 \mu \mathrm{l}$ EB (Qiagen). Fourteen cycles of PCR were performed on $5 \mu \mathrm{l}$ of the immunoprecipitated DNA using the singleend Illumina PCR primers. The resulting products were purified with Qiagen MinElute columns, after which a final size selection (300-1000 bp) was performed by electrophoresis in $2 \%$ agarose. Libraries were quality controlled by Agilent 2100 Bioanalyzer.

For sequencing, the library was denatured with $0.1 \mathrm{M} \mathrm{NaOH}$ to generate singlestranded DNA molecules and loaded onto channels of the flow cell at $8 \mathrm{pM}$ concentrations, amplified in situ using TruSeq Rapid SRCluster Kit (GD-402-4001, Illumina). Sequencing was carried out by running 150 cycles on Illumina HiSeq 2500 using TruSeq Rapid SBS Kit (FC-402-4001, Illumina) according to the manufacturer's instructions.

After sequencing images generated, the stages of image analysis and base calling were performed using Off-Line Base caller software (OLB V1.8). After passing the Solexa CHASTITY quality filter, the clean reads were aligned to mm10 using BOWTIE software (V2.1.0). Aligned reads were used for peak calling, both mRNA and LncRNA associated hMeDIP enriched regions (peaks) with statistically significant were identified for each sample, using a $q$-value threshold of $10^{-4}$ by MACS v2 (http://liulab.dfci.harvard.edu/MACS). Both mRNA and LncRNA associated hMeDIP enriched regions (peaks) were annotated by the nearest gene using the newest UCSC RefSeq database. Differentially hydroxymethylated regions (DhMRs) between two groups with statistically significant were identified by diffReps (Cut-off: $\log _{2} \mathrm{FC}=1.0, p$ value $=10^{-4}$ ). DhMRs were annotated by the nearest gene using the UCSC RefSeq and database of multiple databases integration.

qPCR assay for loci-specific $5 \mathrm{hm} C$ modification. To further confirm the loci-specific hydroxymethylation identified in hMeDIP-sequencing, we tested the $5 \mathrm{hmC}$ level by qPCR with BisulPlus ${ }^{\mathrm{TM}}$ Loci $5 \mathrm{mC}$ and $5 \mathrm{hmC}$ Detection PCR Kit (EpiGentek, \#P-1067). Briefly, $200 \mathrm{ng}$ genomic DNA from OPCs were subjected to bisulfite modification according to the protocol and cleaned up for enzyme conversion. During DNA bisulfite treatment, unmodified cytosine (C) is converted to uracil and will be read as $\mathrm{T}$ in the PCR; $5 \mathrm{mC}$ remains the same and $5 \mathrm{hmC}$ forms cytosine 5-methylenesulfonate (CMS). Further treatment with specific APOBEC deaminase will convert $5 \mathrm{mC}$ to thymine but not affect CMS. The bisulfite-enzyme converted DNA can then be used for qPCR of loci-specific detection of $5 \mathrm{hmC}$ and $\sim 10 \mathrm{ng}$ DNA template was used in each PCR reaction, under standard thermal conditions (7 min hot start, $95^{\circ} \mathrm{C}$ denaturation for $10 \mathrm{~s}, 53.5^{\circ} \mathrm{C}$ annealing temp, and $72^{\circ} \mathrm{C}$ extension for 50 cycles, $72{ }^{\circ} \mathrm{C}$ final extension for $1 \mathrm{~min}$ ) in a $20 \mu \mathrm{l}$ reaction. During the PCR, CMS will still be read as $\mathrm{C}$ so that $5 \mathrm{hmC}$ can be discriminated not only from $\mathrm{C}, 5 \mathrm{mC}$ but also other modified cytosines such as $5 \mathrm{fC}$ and $5 \mathrm{caC}$. The primer's design follows the same criteria for Bisulfite conversion-based methylation-specific PCR (MSP) ${ }^{97}$ and selected with MethPrimer (http://www.urogene.org/ methprimer/index.html). Primers were listed in Supplementary Table 1. Two pairs of primers are needed, one is specific for modified and hydroxymethylated DNA, and the other for modified and unhydroxymethylated DNA. We calculate 5hmC abundance using the following equation:

Relative $5 \mathrm{hmC}$ abundane $=2^{\left[\left(\mathrm{Ct}_{\mathrm{OPC}} \text { methyated }-\mathrm{Ct}_{\mathrm{OPC}} \text { unmethyated }\right)-\left(\mathrm{C}_{\mathrm{NPC}} \text { methyyated }-\mathrm{Ct}_{\mathrm{NPC}} \text { ummethyated }\right)\right]}$

Cut \& Run-seq and data processing. Cut \& Run-seq was performed following the published protocol ${ }^{98}$. Two million OPCs were harvested by centrifugation $(600 \mathrm{xg}$ $3 \mathrm{~min}$ ) and cells were washed twice in $1 \mathrm{ml}$ Wash Buffer (20 mM HEPES-KOH pH 7.5; $150 \mathrm{mM} \mathrm{NaCl} ; 0.5 \mathrm{mM}$ Spermidine; $1 \mathrm{x}$ Roche cOmplete ${ }^{\mathrm{TM}}$ ), followed by the addition of $10 \mu \mathrm{l}$ pre-activated concanavalin A coated magnetic beads (Bangs Laboratories-BP531). Tubes were held on a mixing platform at RT for $10 \mathrm{~min}$, then placed on a magnet stand and pulled off the liquid. Cells were resuspended in $100 \mu \mathrm{l}$ cold Antibody Buffer and $1 \mu \mathrm{l}$ antibody (TET1, Active Motif \#61943) was added for incubating on nutator overnight at $4^{\circ} \mathrm{C}$. Beads with cells were washed twice in $1 \mathrm{ml}$ Digitonin Buffer (20 mM HEPES-KOH pH 7.5; $150 \mathrm{mM} \mathrm{NaCl}$; $0.5 \mathrm{mM}$ Spermidine; $1 \mathrm{x}$ Roche cOmplete ${ }^{\mathrm{TM}}$; $0.05 \%$ digitonin), and resuspended in $50 \mu \mathrm{l}$ Digitonin Buffer with the addition of $2.5 \mu \mathrm{l}$ CUTANA pAG-MNase (20x stock). After 10 min incubation at RT, samples were washed twice in $1 \mathrm{ml}$ Digitonin Buffer and changed to $50 \mu \mathrm{l}$ cold Digitonin Buffer. Then tubes were placed in a metal block in ice water and quickly mixed with $100 \mathrm{mM} \mathrm{CaCl}_{2}$ to a final concentration of $2 \mathrm{mM}$. The reaction was quenched by the addition of a $50 \mu \mathrm{l}$ Stop Buffer. Cleaved fragments were liberated into the supernatant by incubating the tube for 30 min at $37^{\circ} \mathrm{C}$. DNA fragments were purified by Qiagen MinElute PCR Purification Kit from the supernatant and used for the construction of sequencing libraries. Libraries were prepared for Illumina sequencing with Library Prep for Cut \& Run with NEBNext ${ }^{\circledR}$ Ultra ${ }^{\text {tx }}$ II DNA Library Prep Kit for Illumina ${ }^{\circledast}$ (E7645) and were sequenced by NovaSeq PE150.

Cut \& Run-seq reads in FASTQ format were first subjected to quality control to assess the need for trimming of adapter sequences or bad quality segments. The programs used in these steps were FastQC v0.11.7, Trim Galore! v0.4.2 and cutadapt v1.9.1. The trimmed reads were aligned to the reference rat genome version Rn5 with the program BOWTIE v2.3.4.1. Aligned reads were stripped of duplicate reads with the program sambamba v0.6.8. Peaks were called using the program MACS v2.1.2 with the narrow and broad peaks mode for Cut \& Run-seq.

ER $\left[\mathrm{Ca}^{2+}\right]$ measurement. To monitor internal ER store $\mathrm{Ca}^{2+}$ level, a low-affinity calcium indicator mag-Fluo4-AM kit was used according to the manufacturer's instructions (GENMED Scientifics INC., USA, GMS10267) ${ }^{99}$. Briefly, OPCs grown on the poly-L-lysine-coated 96-well black-walled plate were washed with intracellular-like medium (ICM) with EGTA and loaded with mag-Fluo4-AM at $37^{\circ} \mathrm{C}$ for $45 \mathrm{~min}$. Then cells were washed briefly with ICM and permeabilized by 2 min exposure to $\beta$-escin. After washing with ICM, fluorescence (excitation $488 \mathrm{~nm}$, emission $515 \mathrm{~nm}$ ) was recorded at FlexStation 3 spectrofluorometer (Molecular Devices). The relative fluorescence intensity was determined with the following equation, $\left[\mathrm{Ca}^{2+}\right]=K_{d} \times\left(F-F_{\min }\right) \div\left(F_{\max }-F\right)$, and compared to OPCs from control mice. Dye calibration was achieved by obtaining $F_{\min }$ from blank wells with no cells as a baseline value, and $F_{\max }$ from cells loaded with high $\left[\mathrm{Ca}^{2+}\right]$ as saturated value.

$\left[\mathrm{Ca}^{2+}\right]_{i}$ imaging. Fluo4 was used to measure $\left[\mathrm{Ca}^{2+}\right]_{\mathrm{i}}$ changes. To load cells with $\mathrm{Ca}^{2+}$ probe, cultures were incubated in standard aCSF containing (in $\mathrm{mM}$ ): $\mathrm{NaCl}$ $125, \mathrm{KCl} 3.0, \mathrm{CaCl}_{2} 2.0, \mathrm{MgCl}_{2} 2.0, \mathrm{NaH}_{2} \mathrm{PO} 41.25, \mathrm{NaHCO}_{3} 26$ and glucose 20 , or calcium-free aCSF ( $\mathrm{NaCl} 125, \mathrm{KCl} 3.0, \mathrm{MgCl} 2$ 2.0, $\mathrm{MgSO} 4$ 2.0, $\mathrm{NaH} 2 \mathrm{PO} 41.25$, NaHCO3 26, glucose 20, HEPES 10, and EGTA 10 (pH 7.4), supplemented with $0.03 \%$ Pluronic F-127 and $0.6 \mu \mathrm{M}$ cell-permeable form of indicator (Fluo4-AM, Invitrogen) for $20 \mathrm{~min}$ at $37^{\circ} \mathrm{C}$. After loading, cells were transferred into a recording chamber on the stage of Olympus FV1000 confocal inverted microscope equipped with phase-contrast optics. Measurements started after at least $15 \mathrm{~min}$ storage in aCSF to ensure deesterification of indicators. Fluo4 was excited with a $488 \mathrm{~nm}$ laser and emitted light was collected at $515 \mathrm{~nm}$. A series of sections were collected every $500 \mathrm{~ms}$, at $500 \mathrm{~ms}$ intervals, for $180 \mathrm{~s}$ in total. Pharmacological agents were directly added in aCSF: ATP (Sigma, $100 \mu \mathrm{M})$ or Bay K $8644(10 \mu \mathrm{M})$ $30 \mathrm{~s}$ after the first image was taken. The images were analyzed using the Olympus FV10-ASW 4.1 software. Cell bodies were selected as regions of interest (ROI) and normalized changes of Fluo4 fluorescence intensities were calculated as $\Delta F / F=$ $\left(F-F_{0}\right) / F_{0}$ ( $F$ fluorescence intensity, $F_{0}$ baseline intensity). Data were expressed as means \pm standard deviation (SD), " $n$ " represents the number of responding cells Experiments were performed three times from different cultures and the results were pooled together for analysis. $n>97$ in ATP treatment group and $n>130$ in Bay K 8644 group.

Duplex siRNA transfection. For in vitro Itpr2 knockdown, purified OPCs were transfected with $50 \mathrm{nM}$ duplex siRNA against Itpr2 (sense, $5^{\prime}$ GGUACCAGCUAA ACCUCUUTT $3^{\prime}$; anti-sense, $5^{\prime}$ AAGAGGUUUAGCUGGUACCTT 3') or control 
nontargeting siRNA (Genepharma, Shanghai) using Lipofectamine RNAiMAX (Invitrogen). Six hours after transfection, the cultures were changed to a differentiation medium. Two or four days later, cultures were harvested for qRT-PCR assay or immunocytochemistry as indicated.

Statistics and reproducibility. All statistical analyses were performed in Prism v.8.0 (GraphPad Software, Inc.) and SPSS v.21.0 (IBM Inc.). The normality test was performed by the Shapiro-Wilk test and the homogeneity of variance test was performed by Levene's test. All data met normality and homogeneity of variance were compared using a two-tailed unpaired $t$-test and RMANOVA. Data sets that were normal distribution but not homogeneity of variance were compared using a two-tailed unpaired separate variance estimation $t$-test. Data that didn't meet normal distribution were analyzed with Mann-Whitney $U$-test or Friedman $M$ test. Numerical values were described using mean \pm SEM and presented as bar graphs. Significance is denoted as $* p<0.05, * * p<0.01$, or $* * * p<0.001$ in the figures.

For all quantifications in immunostaining and EM, $n=3-5$ animals, independent cultures, or transfections were examined as indicated in the figure legends (3-6 images were analyzed and averaged per mouse or culture, for each staining). All statistical details for each graph can be found in the figure legends. qRT-PCR on cell cultures have been replicated three times in independent experiments.

Reporting Summary. Further information on research design is available in the Nature Research Reporting Summary linked to this article.

\section{Data availability}

The transcriptome, DNA hydroxymethylation profiling, and Cut \& Run-seq data generated in this study have been deposited in the Gene Expression Omnibus database under accession code GSE122838. Previously published and deposited data for hMe-Sealseq of WT NSCs were extracted from GSE65994 and ChIP-seq of H3K27ac were extracted from GSE42454. The data supporting this study are available in the Article, Supplementary Information, or available from the corresponding authors upon reasonable requests. Source data are provided with this paper.

Received: 2 February 2020; Accepted: 5 August 2021;

Published online: 24 August 2021

\section{References}

1. Nave, K. A. \& Werner, H. B. Myelination of the nervous system: mechanisms and functions. Annu Rev. Cell Dev. Biol. 30, 503-533 (2014).

2. Emery, B. \& Lu, Q. R. Transcriptional and epigenetic regulation of oligodendrocyte development and myelination in the central nervous system. Cold Spring Harb. Perspect. Biol. 7, a020461 (2015).

3. Zuchero, J. B. \& Barres, B. A. Intrinsic and extrinsic control of oligodendrocyte development. Curr. Opin. Neurobiol. 23, 914-920 (2013).

4. Gregath, A. \& Lu, Q. R. Epigenetic modifications-insight into oligodendrocyte lineage progression, regeneration, and disease. FEBS Lett. 592, 1063-1078 (2018).

5. Liu, J., Moyon, S., Hernandez, M. \& Casaccia, P. Epigenetic control of oligodendrocyte development: adding new players to old keepers. Curr. Opin. Neurobiol. 39, 133-138 (2016).

6. Lu, G. et al. Epigenetic regulation of myelination in health and disease. Eur. J. Neurosci. 49, 1371-1387 (2019).

7. Iurlaro, M., von Meyenn, F. \& Reik, W. DNA methylation homeostasis in human and mouse development. Curr. Opin. Genet. Dev. 43, 101-109 (2017).

8. Smith, Z. D. \& Meissner, A. DNA methylation: roles in mammalian development. Nat. Rev. Genet 14, 204-220 (2013).

9. Moyon, S. et al. Functional characterization of DNA methylation in the oligodendrocyte lineage. Cell Rep. 15, 748-760 (2016).

10. Kriaucionis, S. \& Heintz, N. The nuclear DNA base 5-hydroxymethylcytosine is present in Purkinje neurons and the brain. Science 324, 929-930 (2009).

11. Tahiliani, M. et al. Conversion of 5-methylcytosine to 5-hydroxymethylcytosine in mammalian DNA by MLL partner TET1. Science 324, 930-935 (2009).

12. Ito, $\mathrm{S}$. et al. Role of Tet proteins in $5 \mathrm{mC}$ to $5 \mathrm{hmC}$ conversion, ES-cell selfrenewal and inner cell mass specification. Nature 466, 1129-1133 (2010).

13. Graff, J., Kim, D., Dobbin, M. M. \& Tsai, L. H. Epigenetic regulation of gene expression in physiological and pathological brain processes. Physiol. Rev. 91, 603-649 (2011).

14. Sun, W., Zang, L., Shu, Q. \& Li, X. From development to diseases: the role of $5 \mathrm{hmC}$ in brain. Genomics 104, 347-351 (2014).

15. Szulwach, K. E. et al. 5-hmC-mediated epigenetic dynamics during postnatal neurodevelopment and aging. Nat. Neurosci. 14, 1607-1616 (2011).

16. Zhao, X. et al. Dynamics of ten-eleven translocation hydroxylase family proteins and 5-hydroxymethylcytosine in oligodendrocyte differentiation. Glia 62, 914-926 (2014).
17. Ficz, G. et al. Dynamic regulation of 5-hydroxymethylcytosine in mouse ES cells and during differentiation. Nature 473, 398-402 (2011).

18. Gu, T. P. et al. The role of Tet 3 DNA dioxygenase in epigenetic reprogramming by oocytes. Nature 477, 606-610 (2011).

19. Li, X. et al. Ten-eleven translocation 2 interacts with forkhead box O3 and regulates adult neurogenesis. Nat. Commun. 8, 15903 (2017).

20. Chen, Y. et al. The oligodendrocyte-specific G protein-coupled receptor GPR17 is a cell-intrinsic timer of myelination. Nat. Neurosci. 12, 1398-1406 (2009).

21. Mogha, A., D’Rozario, M. \& Monk, K. R. G. Protein-coupled receptors in myelinating glia. Trends Pharm. Sci. 37, 977-987 (2016).

22. Zhang, Y. et al. An RNA-sequencing transcriptome and splicing database of glia, neurons, and vascular cells of the cerebral cortex. J. Neurosci. 34, 11929-11947 (2014)

23. Moyon, S. et al. TET1-mediated DNA hydroxymethylation regulates adult remyelination in mice. Nat. Commun. 12, 3359 (2021).

24. Zhang, R. R. et al. Tet1 regulates adult hippocampal neurogenesis and cognition. Cell Stem Cell 13, 237-245 (2013).

25. Xin, M. et al. Myelinogenesis and axonal recognition by oligodendrocytes in brain are uncoupled in Olig1-null mice. J. Neurosci. 25, 1354-1365 (2005).

26. Devaux, J., Gola, M., Jacquet, G. \& Crest, M. Effects of K+ channel blocker on developing rat myelinated CNS axons: identification of four types of $\mathrm{K}+$ channels. J. Neurophysiol. 87, 1376-1385 (2002).

27. Devaux, J. \& Gow, A. Tight junctions potentiate the insulative properties of small CNS myelinated axons. J. Cell Biol. 183, 909-921 (2008).

28. Rustad, S. R., Papale, L. A. \& Alisch, R. S. DNA methylation and hydroxymethylation and behavior. Curr. Top. Behav. Neurosci. 42, 51-82 (2019)

29. Madrid, A., Papale, L. A. \& Alisch, R. S. New hope: the emerging role of 5-hydroxymethylcytosine in mental health and disease. Epigenomics $\mathbf{8}$, 981-991 (2016).

30. Antunes, C., Sousa, N., Pinto, L. \& Marques, C. J. TET enzymes in neurophysiology and brain function. Neurosci. Biobehav. Rev. 102, 337-344 (2019).

31. $\mathrm{Li}, \mathrm{C}$. et al. Assessment of a combination of serum proteins as potential biomarkers to clinically predict Schizophrenia. Int. J. Med. Sci. 15, 900-906 (2018).

32. Mena, A. et al. Reduced prepulse inhibition as a biomarker of schizophrenia Front. Behav. Neurosci. 10, 202 (2016)

33. Vorhees, C. V. \& Williams, M. T. Morris water maze: procedures for assessing spatial and related forms of learning and memory. Nat. Protoc. 1, 848-858 (2006).

34. Chrysanthou, S. et al. A critical role of TET $1 / 2$ proteins in cell-cycle progression of trophoblast stem cells. Stem Cell Reports 10, 1355-1368 (2018)

35. Zhu, X. et al. Age-dependent fate and lineage restriction of single NG2 cells Development 138, 745-753 (2011).

36. Hahn, M. A. et al. Dynamics of 5-hydroxymethylcytosine and chromatin marks in Mammalian neurogenesis. Cell Rep. 3, 291-300 (2013).

37. Hornig, J. et al. The transcription factors Sox10 and Myrf define an essential regulatory network module in differentiating oligodendrocytes. PLoS Genet. 9, e1003907 (2013).

38. Morita, J. et al. Structure and biological function of ENPP6, a choline-specific glycerophosphodiester-phosphodiesterase. Sci. Rep. 6, 20995 (2016).

39. Skene, P. J. \& Henikoff, S. An efficient targeted nuclease strategy for highresolution mapping of DNA binding sites. Elife 6, e21856 (2017).

40. Larson, V. A., Zhang, Y. \& Bergles, D. E. Electrophysiological properties of NG2(+) cells: matching physiological studies with gene expression profiles. Brain Res. 1638, 138-160 (2016).

41. Cheli, V. T. et al. Conditional deletion of the L-type calcium channel Cav1.2 in oligodendrocyte progenitor cells affects postnatal myelination in mice. $J$. Neurosci. 36, 10853-10869 (2016)

42. Cheli, V. T., Santiago Gonzalez, D. A., Spreuer, V. \& Paez, P. M. Voltage-gated $\mathrm{Ca} 2+$ entry promotes oligodendrocyte progenitor cell maturation and myelination in vitro. Exp. Neurol. 265, 69-83 (2015).

43. Zeisel, A. et al. Brain structure. Cell types in the mouse cortex and hippocampus revealed by single-cell RNA-seq. Science 347, 1138-1142 (2015).

44. Marques, S. et al. Oligodendrocyte heterogeneity in the mouse juvenile and adult central nervous system. Science 352, 1326-1329 (2016).

45. Kirischuk, S., Scherer, J., Kettenmann, H. \& Verkhratsky, A. Activation of P2purinoreceptors triggered $\mathrm{Ca} 2+$ release from InsP3-sensitive internal stores in mammalian oligodendrocytes. J. Physiol. 483, 41-57 (1995).

46. Stevens, B., Porta, S., Haak, L. L., Gallo, V. \& Fields, R. D. Adenosine: a neuron-glial transmitter promoting myelination in the CNS in response to action potentials. Neuron 36, 855-868 (2002).

47. Li, N., Sul, J. Y. \& Haydon, P. G. A calcium-induced calcium influx factor, nitric oxide, modulates the refilling of calcium stores in astrocytes. J. Neurosci. 23, 10302-10310 (2003).

48. Greenberg, D. A., Cooper, E. C. \& Carpenter, C. L. Calcium channel 'agonist' BAY K 8644 inhibits calcium antagonist binding to brain and PC12 cell membranes. Brain Res. 305, 365-368 (1984). 
49. Ding, Z. et al. Binding of inositol 1,4,5-trisphosphate (IP3) and adenophostin A to the N-terminal region of the IP3 receptor: thermodynamic analysis using fluorescence polarization with a novel IP3 receptor ligand. Mol. Pharmacol. 77, 995-1004 (2010).

50. Gopalakrishnan, S., Van Emburgh, B. O. \& Robertson, K. D. DNA methylation in development and human disease. Mutat. Res. 647, 30-38 (2008).

51. Lu, H., Liu, X., Deng, Y. \& Qing, H. DNA methylation, a hand behind neurodegenerative diseases. Front. Aging Neurosci. 5, 85 (2013).

52. Towers, A. J. et al. Epigenetic dysregulation of Oxtr in Tet1-deficient mice has implications for neuropsychiatric disorders. JCI Insight 3, e120592 (2018).

53. Zhang, W. et al. Isoform switch of TET1 regulates DNA demethylation and mouse development. Mol. Cell 6, 1062-1073 (2016).

54. Dugas, J. C. et al. Dicerl and miR-219 Are required for normal oligodendrocyte differentiation and myelination. Neuron 65, 597-611 (2010).

55. Bennin, D. A. et al. Cyclin G2 associates with protein phosphatase $2 \mathrm{~A}$ catalytic and regulatory B' subunits in active complexes and induces nuclear aberrations and a G1/S phase cell cycle arrest. J. Biol. Chem. 277, 27449-27467 (2002).

56. Boutros, R. et al. CDC25B overexpression stabilises centrin 2 and promotes the formation of excess centriolar foci. PLoS ONE 8, e67822 (2013).

57. Kalaszczynska, I. et al. Cyclin A is redundant in fibroblasts but essential in hematopoietic and embryonic stem cells. Cell 138, 352-365 (2009).

58. Ayad, N. G. et al. Tome-1, a trigger of mitotic entry, is degraded during G1 via the APC. Cell 113, 101-113 (2003).

59. Timofeev, O., Cizmecioglu, O., Settele, F., Kempf, T. \& Hoffmann, I. Cdc25 phosphatases are required for timely assembly of CDK1-cyclin B at the G2/M transition. J. Biol. Chem. 285, 16978-16990 (2010).

60. Moore, J. D., Kirk, J. A. \& Hunt, T. Unmasking the S-phase-promoting potential of cyclin B1. Science 300, 987-990 (2003).

61. Huang, $\mathrm{S}$. et al. Tet1 is required for Rb phosphorylation during G1/S phase transition. Biochem. Biophys. Res. Commun. 434, 241-244 (2013).

62. Harripaul, R. et al. Mapping autosomal recessive intellectual disability: combined microarray and exome sequencing identifies 26 novel candidate genes in 192 consanguineous families. Mol. Psychiatry 23, 973-984 (2018).

63. Rudenko, A. et al. Tet1 is critical for neuronal activity-regulated gene expression and memory extinction. Neuron 79, 1109-1122 (2013).

64. Powell, S. B., Zhou, X. \& Geyer, M. A. Prepulse inhibition and genetic mouse models of schizophrenia. Behav. Brain Res. 204, 282-294 (2009).

65. van den Buuse, M. Modeling the positive symptoms of schizophrenia in genetically modified mice: pharmacology and methodology aspects. Schizophr. Bull. 36, 246-270 (2010).

66. Marder, S. R. \& Fenton, W. Measurement and treatment research to improve Cognition in Schizophrenia: NIMH MATRICS initiative to support the development of agents for improving cognition in schizophrenia. Schizophr. Res. 72, 5-9 (2004).

67. Mintz, J. \& Kopelowicz, A. CUtLASS confirms CATIE. Arch. Gen. Psychiatry 64, 978 (2007). author reply 979-980.

68. Lesh, T. A., Niendam, T. A., Minzenberg, M. J. \& Carter, C. S. Cognitive control deficits in schizophrenia: mechanisms and meaning. Neuropsychopharmacol. 36, 316-338 (2011).

69. Shi, D. Q., Ali, I., Tang, J. \& Yang, W. C. New insights into 5hmC DNA modification: generation, distribution and function. Front. Genet. 8, 100 (2017).

70. Stroud, H., Feng, S. H., Kinney, S. M., Pradhan, S. \& Jacobsen, S. E. 5 -Hydroxymethylcytosine is associated with enhancers and gene bodies in human embryonic stem cells. Genome Biol. 12, R54 (2011).

71. Tan, L. et al. Genome-wide comparison of DNA hydroxymethylation in mouse embryonic stem cells and neural progenitor cells by a new comparative hMeDIP-seq method. Nucleic Acids Res. 41, e84 (2013).

72. Song, C. X. et al. Selective chemical labeling reveals the genome-wide distribution of 5-hydroxymethylcytosine. Nat. Biotechnol. 29, 68-72 (2011).

73. Nestor, C. E. et al. Tissue type is a major modifier of the 5-hydroxymethylcytosine content of human genes. Genome Res. 22, 467-477 (2012).

74. Jin, S. G., Wu, X., Li, A. X. \& Pfeifer, G. P. Genomic mapping of 5-hydroxymethylcytosine in the human brain. Nucleic Acids Res. 39, 5015-5024 (2011).

75. $\mathrm{Xu}$, Y. et al. Genome-wide regulation of $5 \mathrm{hmC}, 5 \mathrm{mC}$, and gene expression by Tet1 hydroxylase in mouse embryonic stem cells. Mol. Cell 42, 451-464 (2011).

76. Pfeifer, G. P., Kadam, S. \& Jin, S. G. 5-hydroxymethylcytosine and its potential roles in development and cancer. Epigenetics Chromatin 6, 10 (2013).

77. Wanunu, M. et al. Discrimination of methylcytosine from hydroxymethylcytosine in DNA molecules. J. Am. Chem. Soc. 133, 486-492 (2011).

78. Lopez, C. M., Lloyd, A. J., Leonard, K. \& Wilkinson, M. J. Differential effect of three base modifications on DNA thermostability revealed by high resolution melting. Anal. Chem. 84, 7336-7342 (2012).
79. Valinluck, V. et al. Oxidative damage to methyl-CpG sequences inhibits the binding of the methyl-CpG binding domain (MBD) of methyl-CpG binding protein 2 (MeCP2). Nucleic Acids Res. 32, 4100-4108 (2004).

80. Jin, S. G., Kadam, S. \& Pfeifer, G. P. Examination of the specificity of DNA methylation profiling techniques towards 5-methylcytosine and 5-hydroxymethylcytosine. Nucleic Acids Res. 38, e125 (2010).

81. Williams, K. et al. TET1 and hydroxymethylcytosine in transcription and DNA methylation fidelity. Nature 473, 343-348 (2011).

82. $\mathrm{Wu}, \mathrm{H}$. et al. Dual functions of Tet1 in transcriptional regulation in mouse embryonic stem cells. Nature 473, 389-393 (2011).

83. Yildirim, O. et al. Mbd3/NURD complex regulates expression of 5-hydroxymethylcytosine marked genes in embryonic stem cells. Cell 147, 1498-1510 (2011).

84. Neri, F. et al. Genome-wide analysis identifies a functional association of Tet1 and Polycomb repressive complex 2 in mouse embryonic stem cells. Genome Biol. 14, R91 (2013).

85. Khoueiry, R. et al. Lineage-specific functions of TET1 in the postimplantation mouse embryo. Nat. Genet. 49, 1061-1072 (2017).

86. Butt, A. M. Neurotransmitter-mediated calcium signalling in oligodendrocyte physiology and pathology. Glia 54, 666-675 (2006).

87. Friess, M. et al. Intracellular ion signaling influences myelin basic protein synthesis in oligodendrocyte precursor cells. Cell Calcium 60, 322-330 (2016).

88. Li, T. et al. Dynamic calcium release from endoplasmic reticulum mediated by ryanodine receptor 3 is crucial for oligodendroglial differentiation. Front. Mol. Neurosci. 11, 162 (2018).

89. Zhang, M., Liu, Y. \& Wu, S. \& Zhao, X. Ca(2+) signaling in oligodendrocyte development. Cell Mol. Neurobiol. 39, 1071-1080 (2019).

90. $\mathrm{Yu}, \mathrm{Y}$. et al. Olig2 targets chromatin remodelers to enhancers to initiate oligodendrocyte differentiation. Cell 152, 248-261 (2013).

91. Futatsugi, A. et al. IP3 receptor types 2 and 3 mediate exocrine secretion underlying energy metabolism. Science 309, 2232-2234 (2005).

92. Emery, B. \& Dugas, J. C. Purification of oligodendrocyte lineage cells from mouse cortices by immunopanning. Cold Spring Harb. Protoc. 2013, 854-868 (2013).

93. Ranscht, B., Clapshaw, P. A., Price, J., Noble, M. \& Seifert, W. Development of oligodendrocytes and Schwann cells studied with a monoclonal antibody against galactocerebroside. Proc. Natl Acad. Sci. USA 79, 2709-2713 (1982).

94. Sommer, I. \& Schachner, M. Monoclonal antibodies (O1 to O4) to oligodendrocyte cell surfaces: an immunocytological study in the central nervous system. Dev. Biol. 83, 311-327 (1981).

95. Evans, R. D., Weston, D. A., McLaughlin, M. \& Brown, A. M. A non-linear regression analysis method for quantitative resolution of the stimulus-evoked compound action potential from rodent optic nerve. J. Neurosci. Methods $\mathbf{1 8 8}$, 174-178 (2010).

96. Down, T. A. et al. A Bayesian deconvolution strategy for immunoprecipitation-based DNA methylome analysis. Nat. Biotechnol. 26, 779-785 (2008).

97. Li, L. C. \& Dahiya, R. MethPrimer: designing primers for methylation PCRs. Bioinformatics 18, 1427-1431 (2002).

98. Brahma, S. \& Henikoff, S. RSC-associated subnucleosomes define MNase-sensitive promoters in yeast. Mol. Cell 73, 238-249 e233 (2019).

99. Rossi, A. M. \& Taylor, C. W. Reliable measurement of free $\mathrm{Ca}(2+)$ concentrations in the ER lumen using Mag-Fluo-4. Cell Calcium 87, 102188 (2020).

\section{Acknowledgements}

This work was supported by the National Natural Science Foundation of China (Grant number: 82071271 and 31571050 to X.Z., 81730035 to S.W.). Q.R.L. was supported by the Cincinnati Children's Hospital Medical Foundation and CancerFree KIDs foundation. The authors would like to thank Dr. Fangfang Liu, Dr. Bo Zhao, Junjun Kang, Ke Fang, and Haifeng Zhang for great technical support; Dr. Natalie Lai Man Wu for GSEA analysis; Dr. Weidong Tian, Dr. Feng Zhang, Dr. Yazhou Wang, Dr. Ceng Lou, Dr. Rougang Xie, Dr. Jinxiang Dai, and Dr. Yaqi Deng for helpful suggestions; and Dr. Guoliang Xu for Tet $1^{\text {loxp }}$ lines.

\section{Author contributions}

Data acquisition, M.Z., J.W., K.Z., G.L., Y.L., K.R., D.X., J.X. and X.G.; Experimenta design, validation, data analysis, visualization, and original draft, M.Z., W.W., L.X., H.M., W.J. and X.Z.; Conceptualization, writing, revisions, and editing, M.Z., K.B., S.W., Q.R.L. and X.Z.; Funding acquisition and supervision, S.W., Q.R.L. and X.Z.; Resources, K.M.

\section{Competing interests}

The authors declare no competing interests. 


\section{Additional information}

Supplementary information The online version contains supplementary material available at https://doi.org/10.1038/s41467-021-25353-5.

Correspondence and requests for materials should be addressed to S.W., Q.R.L. or X.Z.

Peer review information Nature Communications thanks Shin Kang and the other anonymous reviewer(s) for their contribution to the peer review of this work. Peer reviewer reports are available.

Reprints and permission information is available at http://www.nature.com/reprints

Publisher's note Springer Nature remains neutral with regard to jurisdictional claims in published maps and institutional affiliations. (c) (i) Open Access This article is licensed under a Creative Commons Attribution 4.0 International License, which permits use, sharing, adaptation, distribution and reproduction in any medium or format, as long as you give appropriate credit to the original author(s) and the source, provide a link to the Creative Commons license, and indicate if changes were made. The images or other third party material in this article are included in the article's Creative Commons license, unless indicated otherwise in a credit line to the material. If material is not included in the article's Creative Commons license and your intended use is not permitted by statutory regulation or exceeds the permitted use, you will need to obtain permission directly from the copyright holder. To view a copy of this license, visit http://creativecommons.org/ licenses/by/4.0/.

(C) The Author(s) 2021 